
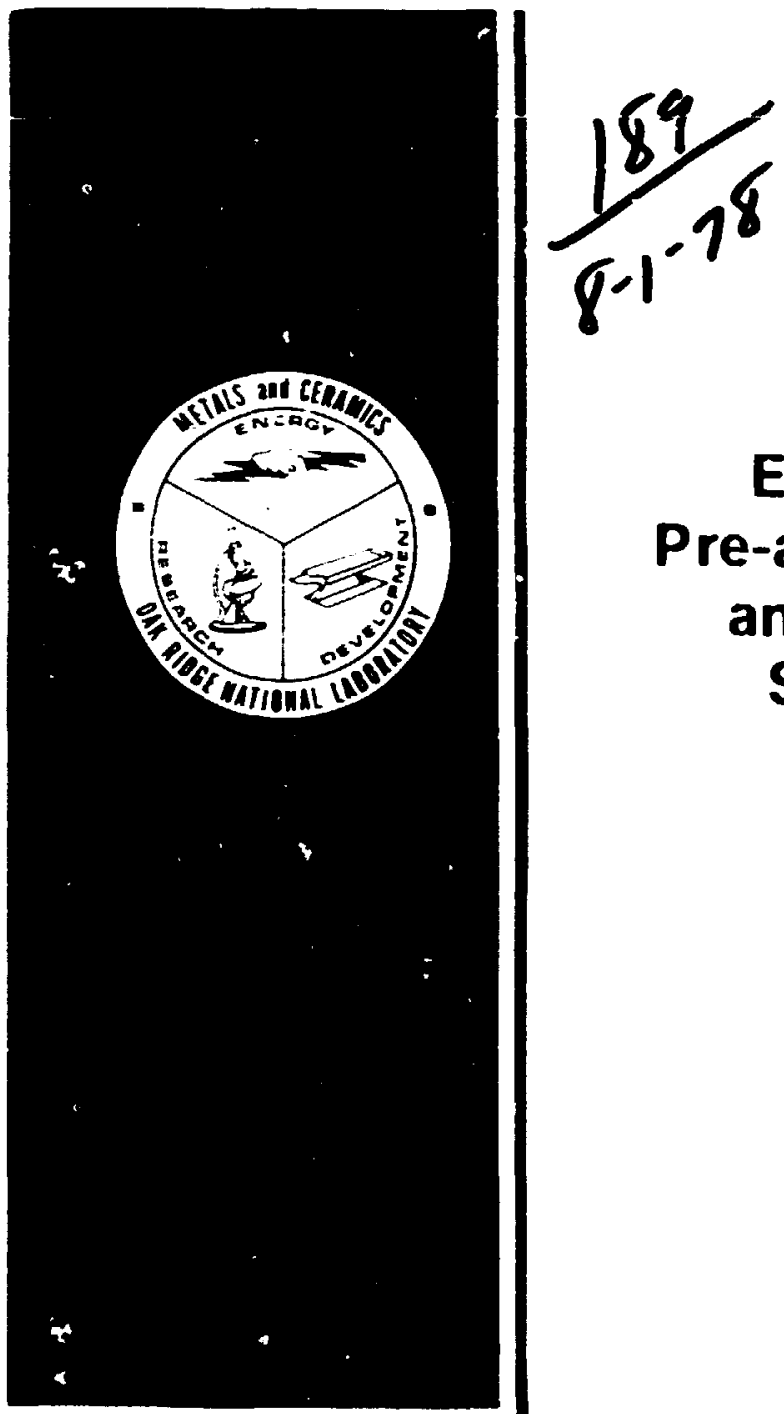

Experimental Determinations of the Pre-and Postirradiation Thermal Transport and Thermal Expansion Properties of Simulated Fuel Rods for an HTGR
J. P. Moore
T. G. Godfrey
R. S. Graves

W. P. Eatherly

E. L. Long. Jr.

F. J. Weaver

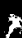

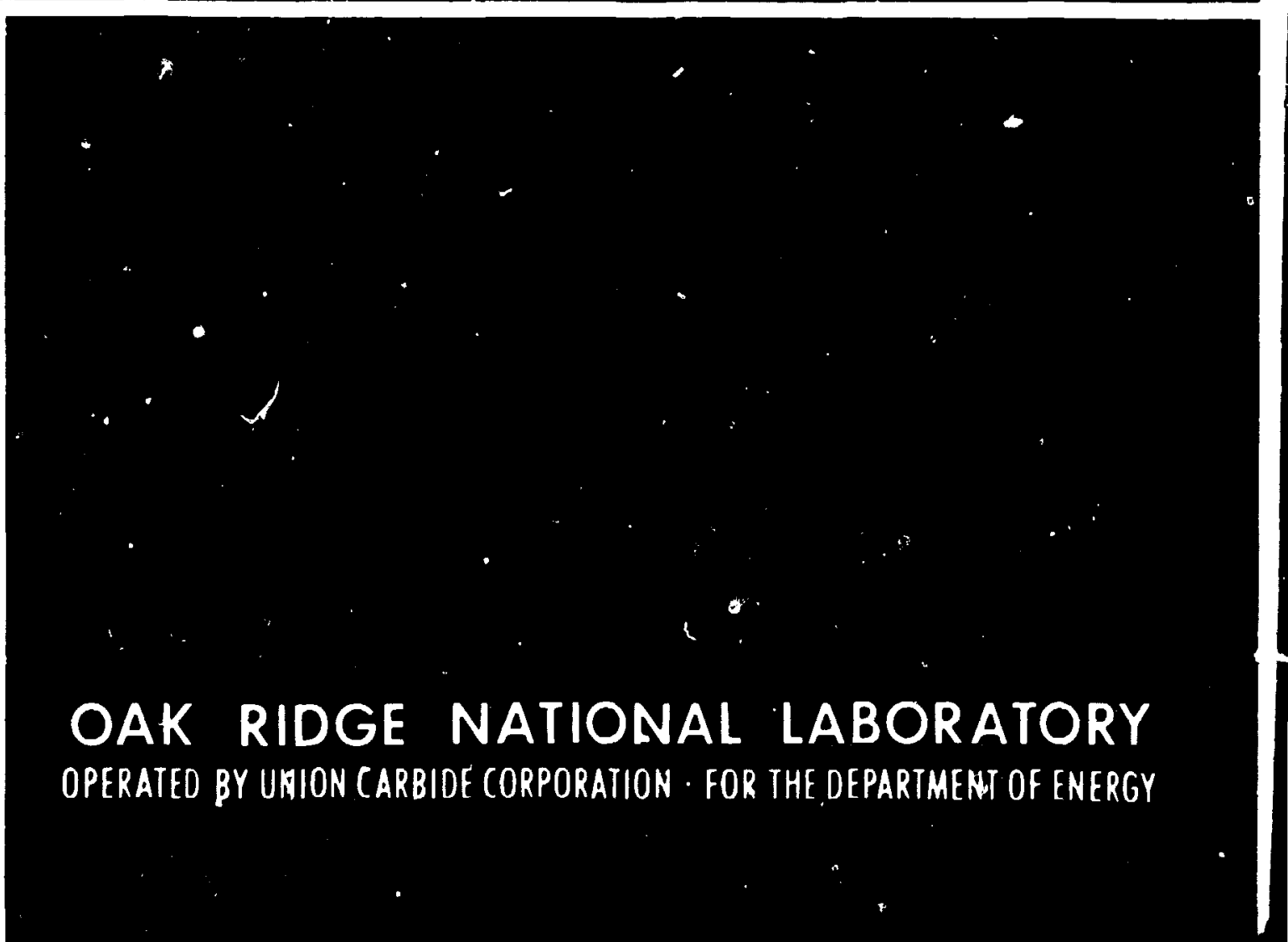



J. P. Moore
R. S. Graves
E. L. Long. Jr.
T. G. Godfrey
W. P. Eatherly
F. J. Weaver

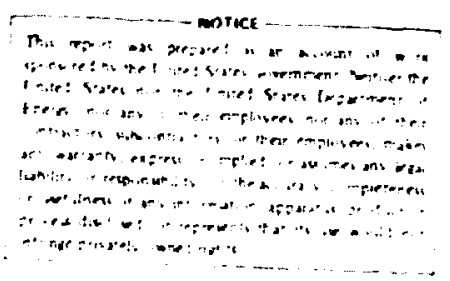

Date Published: July 1972

\author{
OAK RIDGE NATIONAL LABORATOAY \\ Oak Ridge. Tennessee $3783 \mathrm{C}$ \\ operated b" \\ UNION CARBIDE COAPORATION \\ for the \\ DEPARTMENT OF ENERGY
}




\section{CONTE.ITS}

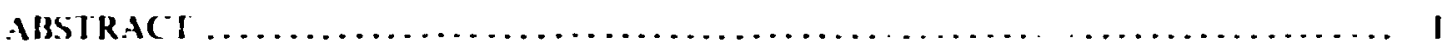

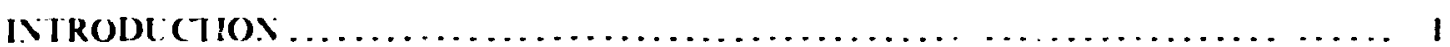

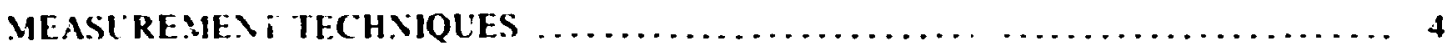

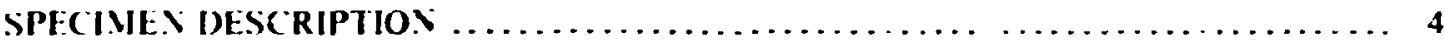

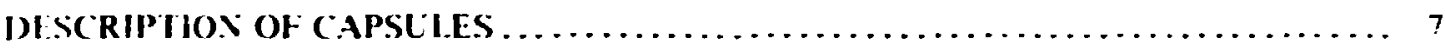

Irradiation Historg...................................... 7

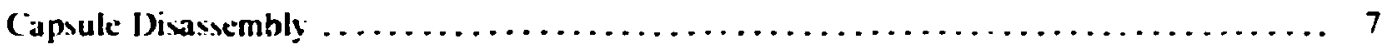

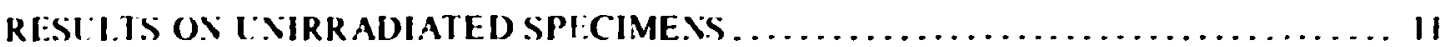

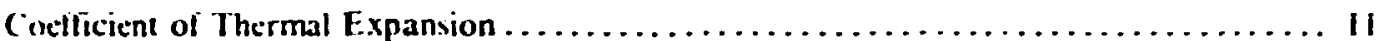

Flectrical Resistis ity and Secheck Coefficient ............................

Therma' Conductivity $\ldots \ldots \ldots \ldots \ldots \ldots \ldots \ldots \ldots \ldots \ldots \ldots \ldots \ldots \ldots \ldots \ldots \ldots \ldots \ldots, 13$

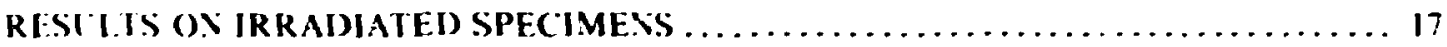

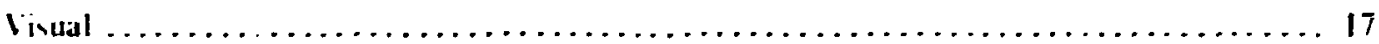

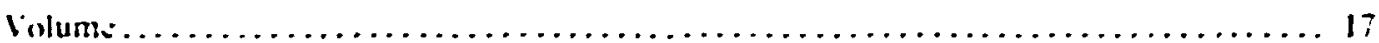

rovillicient of Thermal Expansion ................................. 17

Hlectrical Resistivity........................................ 17

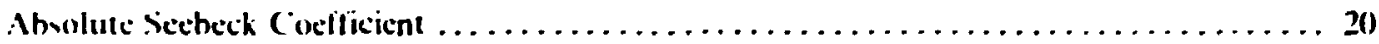

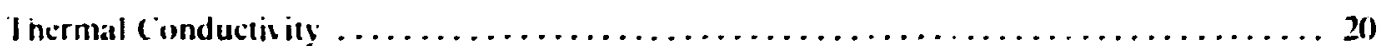

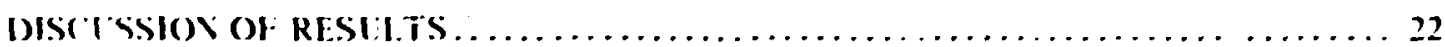

Cocflicient of Thermal Expancior ................................. 22

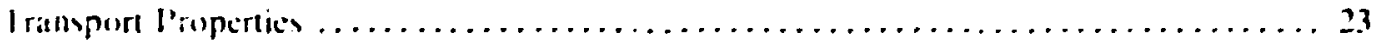

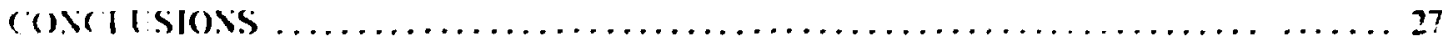

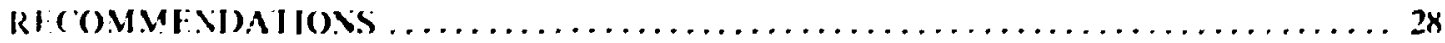

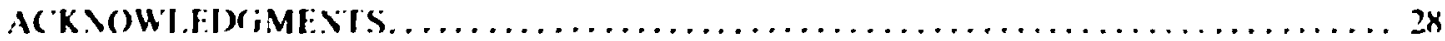

Ippendix A. EXPEPIME.XTAI. DATA ........................... 29

Appendix B. CAI.CLIATION OF AN EFFECTIVE PARTICIE A ASSI MINC THAT Im, B!HAVES AS DOES A OF IHE UNI.OADED SPIE(IMIX............ 33

Appendix ('. IOMAPRISON OF THE ELFCTRICAI. RFSISIIVITIFS OF SI."(:-

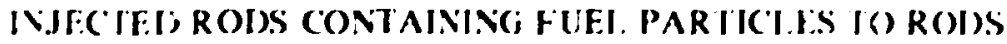

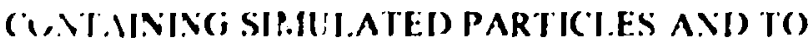

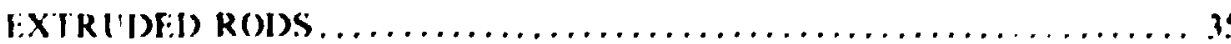




\title{
EXPERIMENTAL DETERMINATIONS OF THE PRE- AND POSTIRRADIATION THERMAL TRANSPORT AND THERMAL EXPANSION PROPERTIES OF SIMULATED FUEL RODS FOR AN HTGR
}

\author{
J. P. Moore. T. G. Godfrex. R. S. Graves. F. J. Weaver. W. P. Eatherly. and E. L. Long. Jr.
}

\begin{abstract}

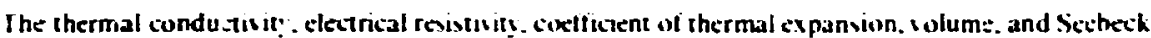
cietlicient of simulated fuel rods for a high-temperature gas-conoled wactor (HT(iR) here measured betore and atter neutron irradiations we $13.5 \%^{\prime} v^{\prime \prime}$ neutrons $m^{\prime}$ at nomina: irradiation temperatures if $1220 \mathrm{~K}$. Thoe measuremenis wete made as iunctions of wolume percent particle loading temperaturs. and neutron nuence. The thermal conductusties decrease uith increasing nasticke loading at all measurement i a rature. The large difference betucen the propertios of specimens from ruo fabrication procisse (extrusion and slug injection) is attributed to the fact that the densitics of the continunus phase whthin the etements difier by a tactor of 2.6 . Increases in the thermal conductivity with initial neutron tluence of some of the extruded specimess are altributed to partial ordering of car bonaceous material u ithin the composites. hut an unambiguous yuantitutwe analysis is difficult. Some electrical resistin ity result, obtand on viug-injected unirradiated fuel rods siun that the thermal conductsily would probably be allected bs graphite shim content. Pres lous incontigators hate ontimated that the thermal conductivity of slug-injectert fuel rods wosuld neser go belisu $6.9 \mathrm{~W} \mathrm{~m} \cdot \mathrm{K}$. but measurements an a slug-injected specinten

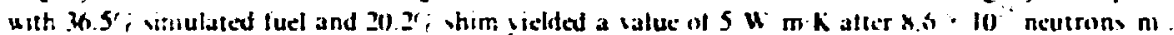

\section{INTRODUCTION}

The phivsical properties of fucl clenuents are imnortant pararaeter in controlling fuel lifetime durihg reactor operation. These propertics usually are functions of (1) temperature. (2) neutron flux. (3) neutron fluence. (4) temperature during neutron irradiation. and (5) fuel element fabrication details. The fuel rods foc prospective high-temperature gas-cooled reactors ( $H T(\mathbf{R})^{\prime}$ are composite materials consisting of pheroidal flecl particles contained in a carbonaceous matrix. In addition. the fuel

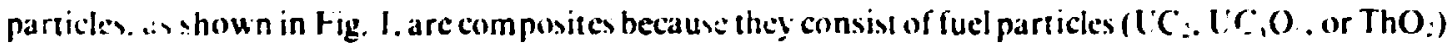
- urrounded hy several coatings designed to retain fission products during the particle lifetime. This crimposite structure leads to properties that are complex functions of time and temperature. Neutron irradiation makes the transport parameters of composites even more complex hy having differen: effects on the individual components such as $1: 0$ : (rel. 2). graphite. and the carbonaceous matrix * During fuel element use, neutron irradiation places a thermal gradiert on the fuel element. and fuel kernels may migrate up : his gradient causing coated particle failure as woon as the fucl pasies through

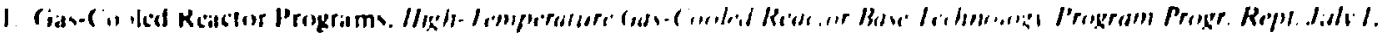

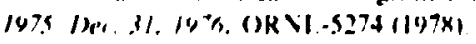

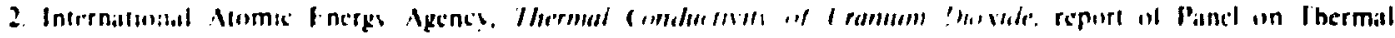

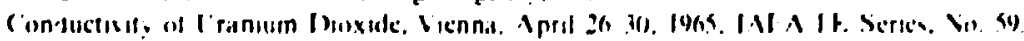

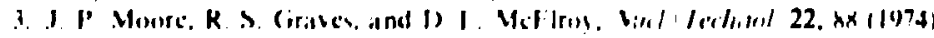

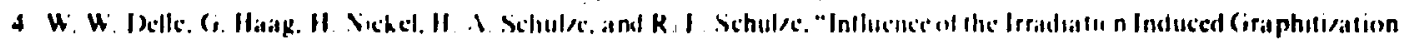

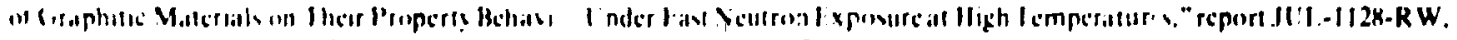

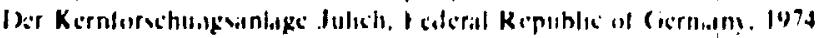




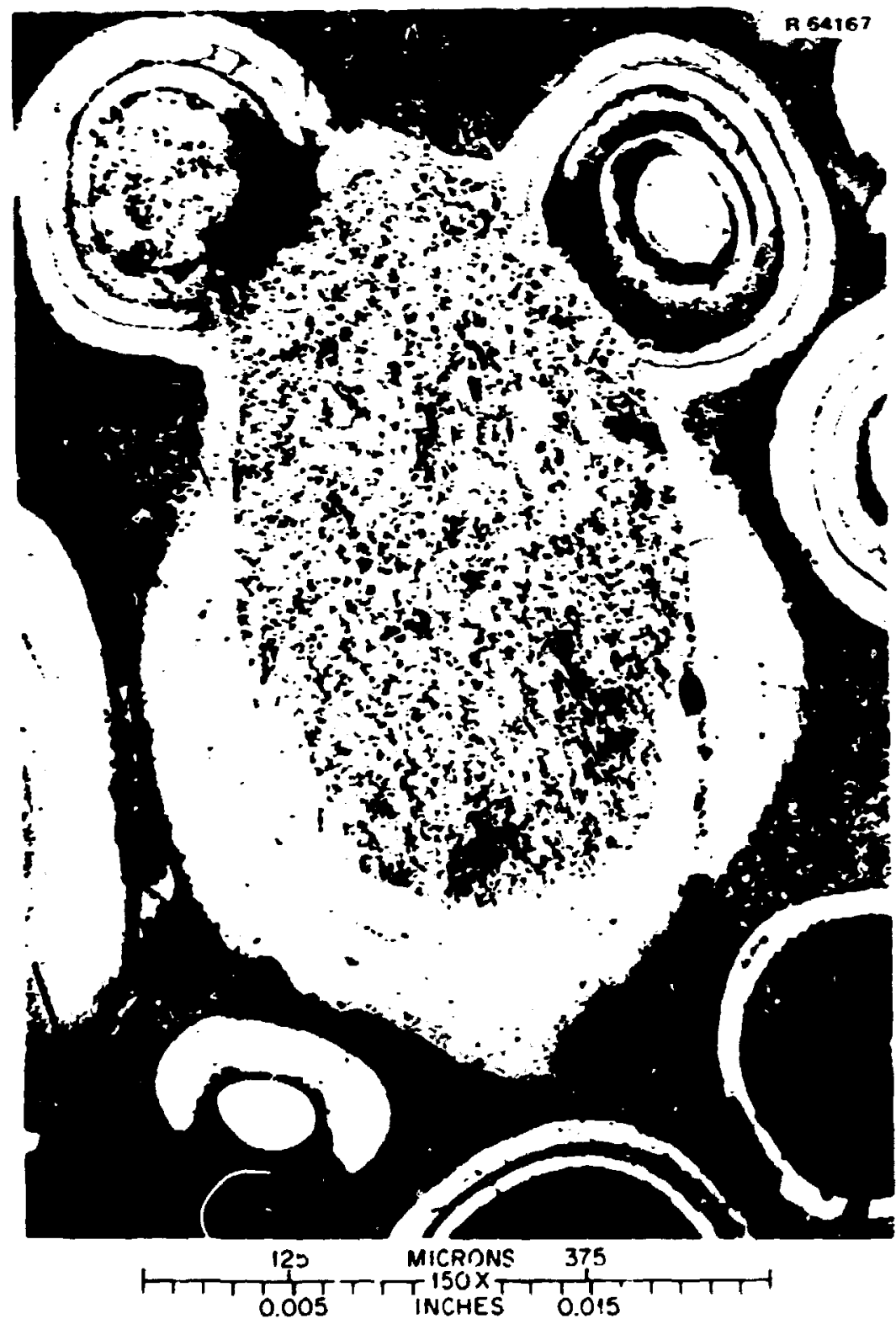

Fig. 2. Ketael migration through its coating and into the adjaten: particles after operation ned: ln2? $K$ with a gradient of about $1.4 \times 10^{3} \mathrm{~K} \mathrm{~m}$.

There are iw.) primary techniques inr fabricating coaled particle fuel rods." The first, and Iraditional. technigue involses pouring coated fuel particles into a mold and then injecting a paste containing graphite flake into the soids between particles. Hecausc peured luel spheres normally consume about $58{ }^{\prime} ;$; of a solume, this lechnique dictals: a volume particke loading of $58{ }^{\circ}$;. When lowar fuel concentration is rey uired, a ceriain fraction of the particles will consist of inert "shims" of graphite.

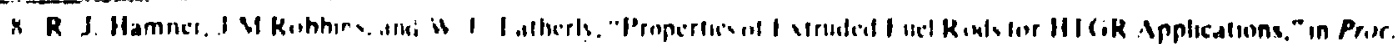

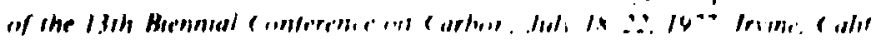


Thus. a thel lodding of :5; ; would mean 35-10l'; fuel particles plus $23-6$ ol'; shim particlew in the clement. This tabrication icchniyue. reterred to as slug enjection. produces a inaterial of lou matris densily

A ecound lechnique tor taci ckement labrication is extrusion. Coatcd fuel particles are mixed in a

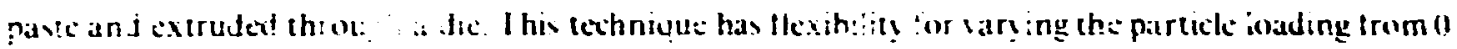

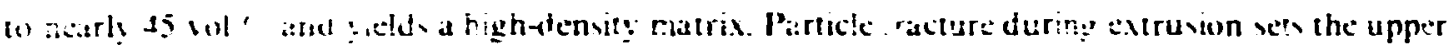
loadin: linut.

The geaf of ihis experiment wa the determination of thermal conduc...tty. $\lambda$ : elecirical resistivity.

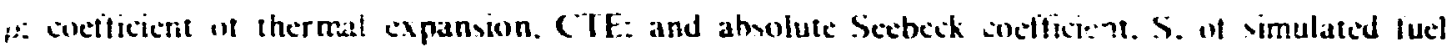
elements tahricated $b$ : thex tho techniques. These determinations uere made as tunctios, of whome percent particle load!reg. iemperature. and neutron fli:ence.

\section{MEASUREMENT TECHNIQIES}

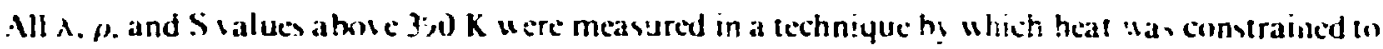
tlow aloug the axls of a pecimen in the shape of at right circular eglimer. Ka fial heat thou was.

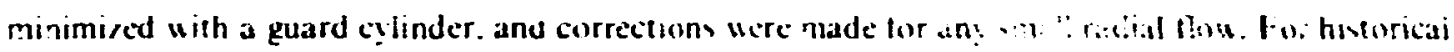
reasons thi icchnique is called the high-temperature iongitudinal $r: a$ :

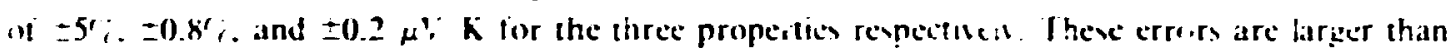
notmally experienced with this lichnique becative the spainen. "ere abnormatity short and he aluse

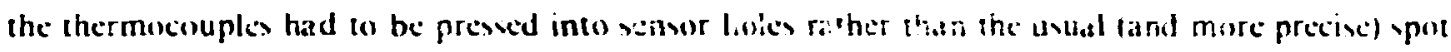
urelding into place. Figure $\mathbf{3}$ shous a specimen with pare st the guard eglinder removed. A heater.

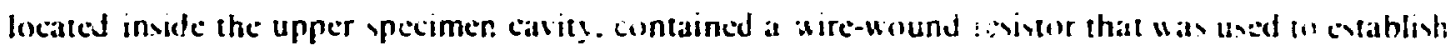
a teriperature gradient along the specimen. The emperature on the guard-e linale beater was automatically controlled to eyual the temperature on the specimen heater so that heat exchange betueen guard crlinder and specimen was minimised. This end was alw accomplished ny in!lng the

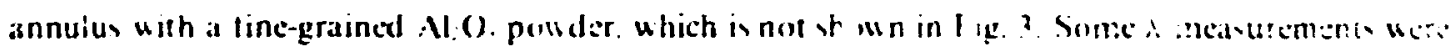

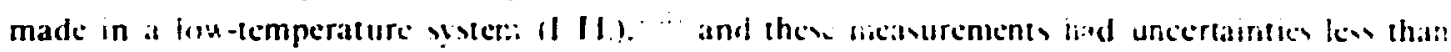
$10)^{\prime}$.

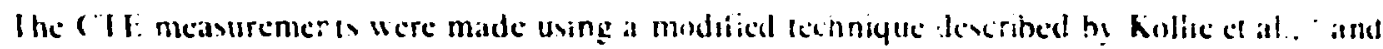
the values hase entimated uncertatntes of $-4 \%$.

\section{SPECIMEN DESCRIPTION}

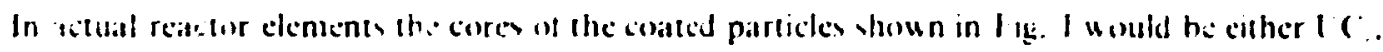

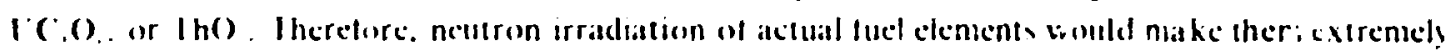

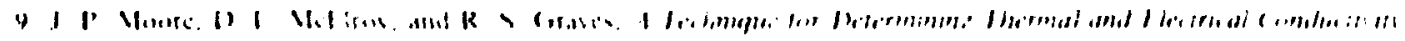

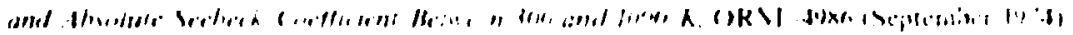

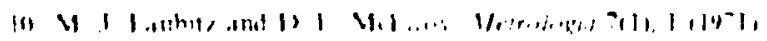

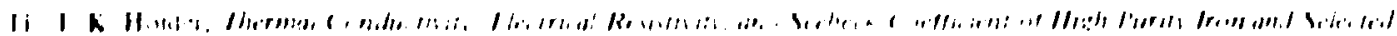

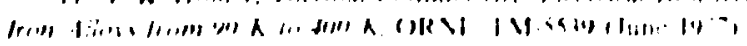

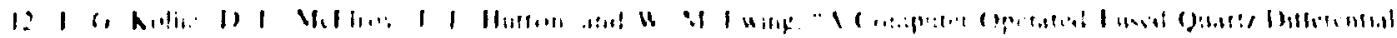

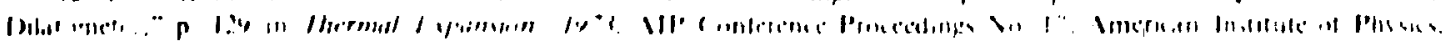
lin ink. $11+4$ 


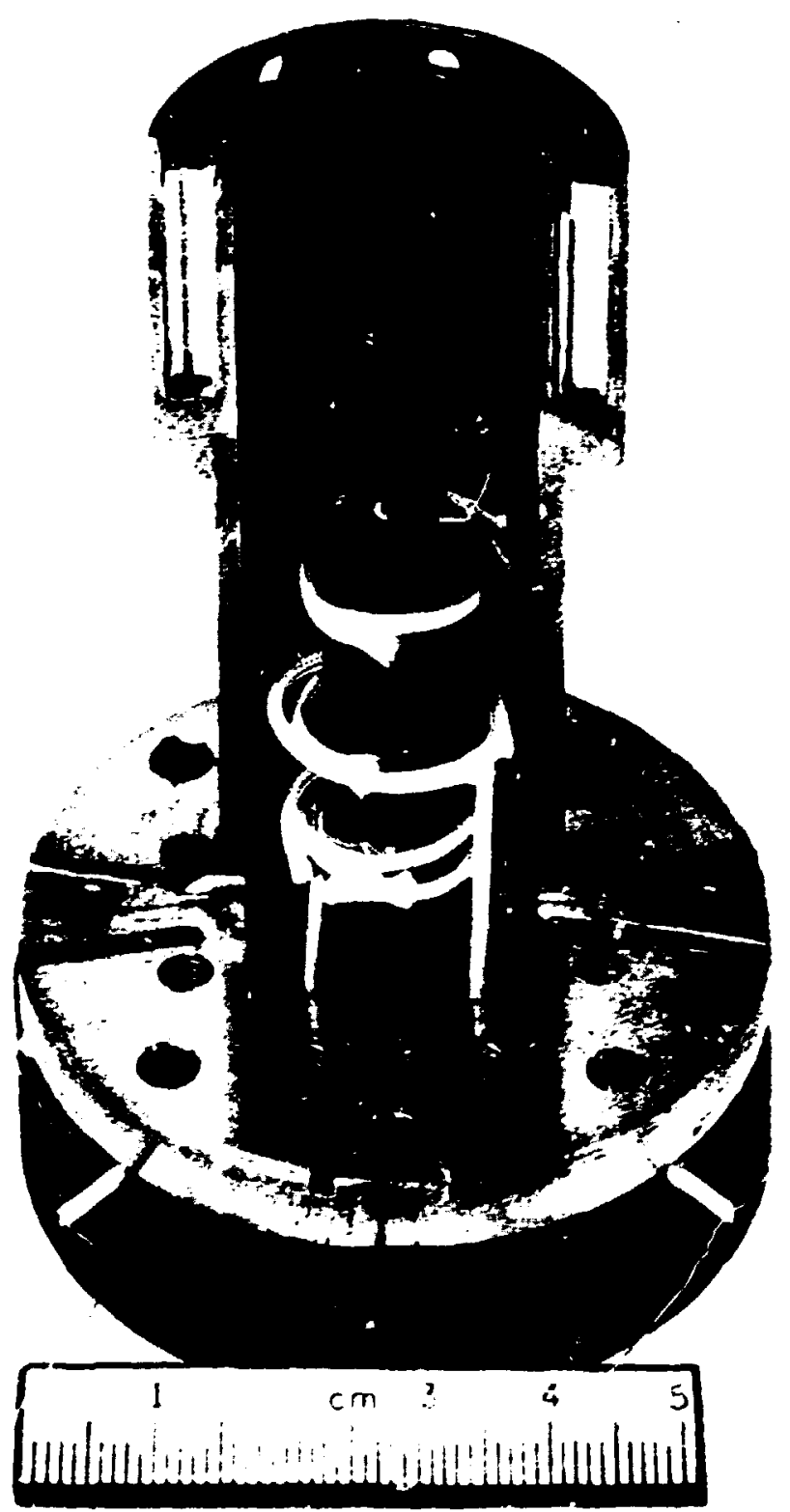

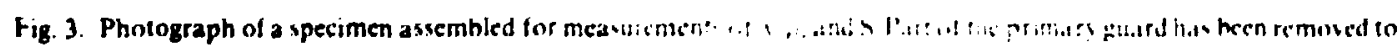

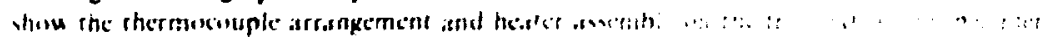

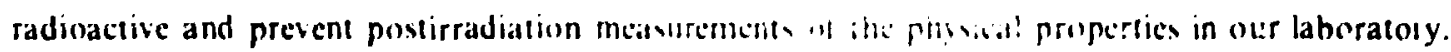

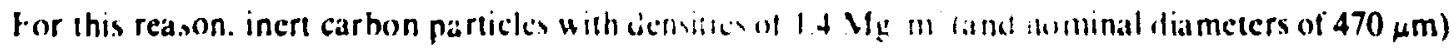
were used for the particle ceres. There carbon heind were heat trealed at $21(0) \mathrm{K}$, and inner and outer

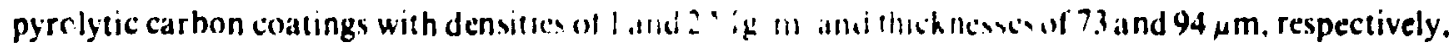
were then applied. These coated particl:e uere heal erealed al $21(0) \mathrm{K}$ for 600 s pricr to bonding into fucl rods. 
The matrix of each yecimen formed by slug injection consisted of 28.5 wi 7 graphite filler " in pitch. : All vlug-injected simulated fuel elements were heat treated at $2100 \mathrm{~K}$ for $1.8 \mathrm{ks}$, which yiclded a final matrix denvit! of $11.6 \mathrm{Mg} \mathrm{m}$.

Simulated tuel rod. "wh nominal volume percent particle loadings of 0. 13. 22. and 35 werc fahricated by the extrusiori process. The matrix of each loading uas a mixture of 75.7 -ut $\%$ graphite." 24.3-ul ", Ihermax." and 25-pph (parts of liquid added per hundred parts of solids being slurried) prepolymerized furfuryl alcohol ( Varcum). After heat treating at $2100 \mathrm{~K}$ in argon for $1.8 \mathrm{ks}$. the matrix densitien were nominally 1.75 .1 .68 .1 .63 , and $1.62 \mathrm{sg} \mathrm{m}^{\text {* }}$ for the extruded specimens $\mathrm{u}$ ith volume percient particle loa ting, af 0. 13. 2) and 35 respectively. All specimens were right-circular cylinders with nominal OI). ID. and !ength of $10.16 \mathrm{~mm}$. $3.175 \mathrm{~mm}$ and $50.8 \mathrm{~mm}$ respectisely:

One was to deterninc the influence of irradiation on a specific property of a material is to measure the property in the unirradiated state. irradiate the same specimen to a known fluence. and then repeat the properiy neasurement. However, as snoun in Fig. 3. the $\lambda$ measurements required at tachment of heater and heat sink to opposite ends of the specimen. These protuberances were large enough to prevent placement in a reactor capsule. Therefore, a large number of each specimen type was made. and the five most uniform and homogeneous specimens of , th loading were selected for the measurement series on ihe premise that neutron thence would have the atme effect in all specimens with the same particle loading.

Table i presents the electrical resistivity of the 25 specimens selected tor this study: these were selected on the basis of their $\rho$ unitormity and the proximity of the of the hatch as rage. The $p$ value for each specim:n is the average of several measurements made at different positions along the elements. Th: number in parentheses is the maximum variation of any measured value from the average $p$. The maximum percentage variations for the extruded specimens are $2.7 \%$; 22 and 35 vol $;$ inirradiated). wh:reas the variations for the specimens from the slug-injection process were generally greater with a high of 5.6\%; for the 57.5-bol'; specimen. which was scheduled for four escles.

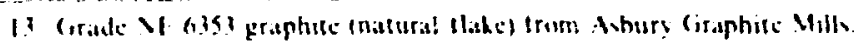

14. (irade 2+1) petroleum pitch irom Ashland (Bl. Ine

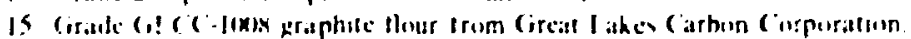

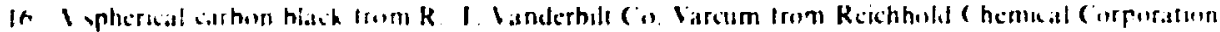

Table I. Average electrical resistivitiea at $300 \mathrm{~K}$ I after final machining) of simutated fuet rods in microhm meters

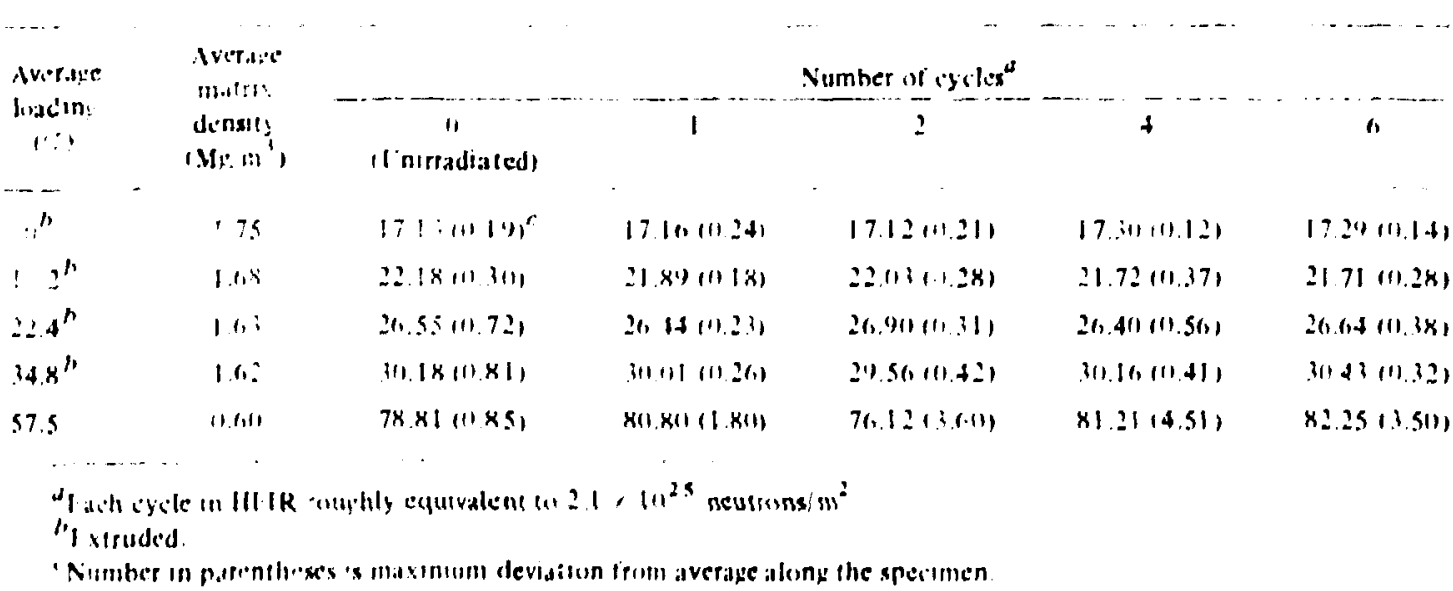


The specimens listed under the ${ }^{-0}{ }^{-}$column of Table I were measured in the unirradiated condition. The remaining 20 specimens were irradiated in HFIR' for the number of cycles listed. All fluence values given are for $E>28.8 \mathrm{fJ}$. The irradiation temperature for each specimen was a nominal $1220 \mathrm{~K}$. The specimens within a given group (i.e.. I cycle. 2 cycle, etc.) did not receive the same neutron fluence because of the flux profile within HFIR: the actual fluence value for each specimen is given later in the repon in Täbles 5. 7. and 8.

\section{DESCRIPTION OF CAPSULES}

This experiment initially consisted of four identical capsules designated HT-20, $-21,-22$ and -23 . Each capsule contained five simulated fuel rods. The capsules were designed to operate isothermally at $1220 \mathrm{~K}$ and were scheduled to be irradiated in the target region of HFIR for $I 2.4$, and 6 cycles. A description of the irradiation facility has been reported previously."

The capsule design used to irradiate the simulated fuel rods is shown in Fig.4. The five simulated fuel Iods were placed symmetrically about the horizontal midplane of the HFIR core. The rods were in landem on a hollow graphite spine with two extruded rods placed above and below a slug-injected rod in each of the capsules. The hollow graphite spines contained tungsten rods that were ga mma heat sources for the simulated fuel rods.

In addition to the rods irradiated in capsules HT-20 through -23 , four additional rods were irradiated in capsules HT-31 and -32 . These additional rods were irradiated to supplement information obtained from HT-20 through -23 and replacements for several reds that were broken during capsule disas iembly. as described in the section on postirradiation examination. Capsule HT-3I contained a slug-injucted rod (58-vol $c_{\text {; }}$ particles) and an extruded rod (35-vol \% particles); the extruded rod had been irradiated previously in HT-22 for four cycles in position 5. Cajsule HT-32 also contained a slug-injected rod (58-vol $c_{r}$ particles) and an extrudec rod (23-vol $C_{c}$ par. -les); the extruded rod had been irradiated previously in HT-23 for two cycles in position 7. The capsule geometry and temperature for these four replacement rods were the same as for those irradiated in HT-20 through -23. A schematic of capsules HT-31 and HT-32 are shown in Fig. 5.

\section{Irradiation History}

The irradiation histories for the target capsules that contained the simulated fuel rods are summaried in Table 2. The calrulated thermal and fast fluence values for the fuel rods are listed in Tabic 3.

\section{Capsule Disassembly}

After irradiation. capsules HT-20 through -23 were trans?erred to the hot cells in Building 3026D for disassembly. Unfortunately, some of the fuel rod specimens were broken during the disassembly operations. The fuel rods had shrunk so much that considerable force was required to remove the graphite spines. which resulted in some damaged or broken specimens.

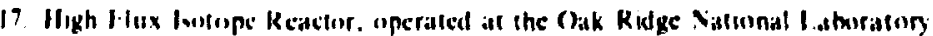

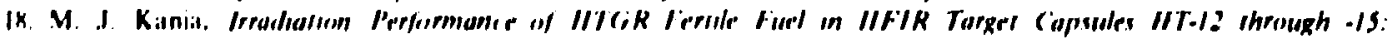

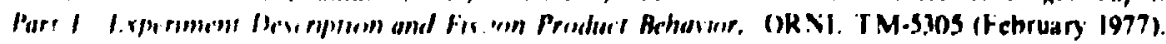




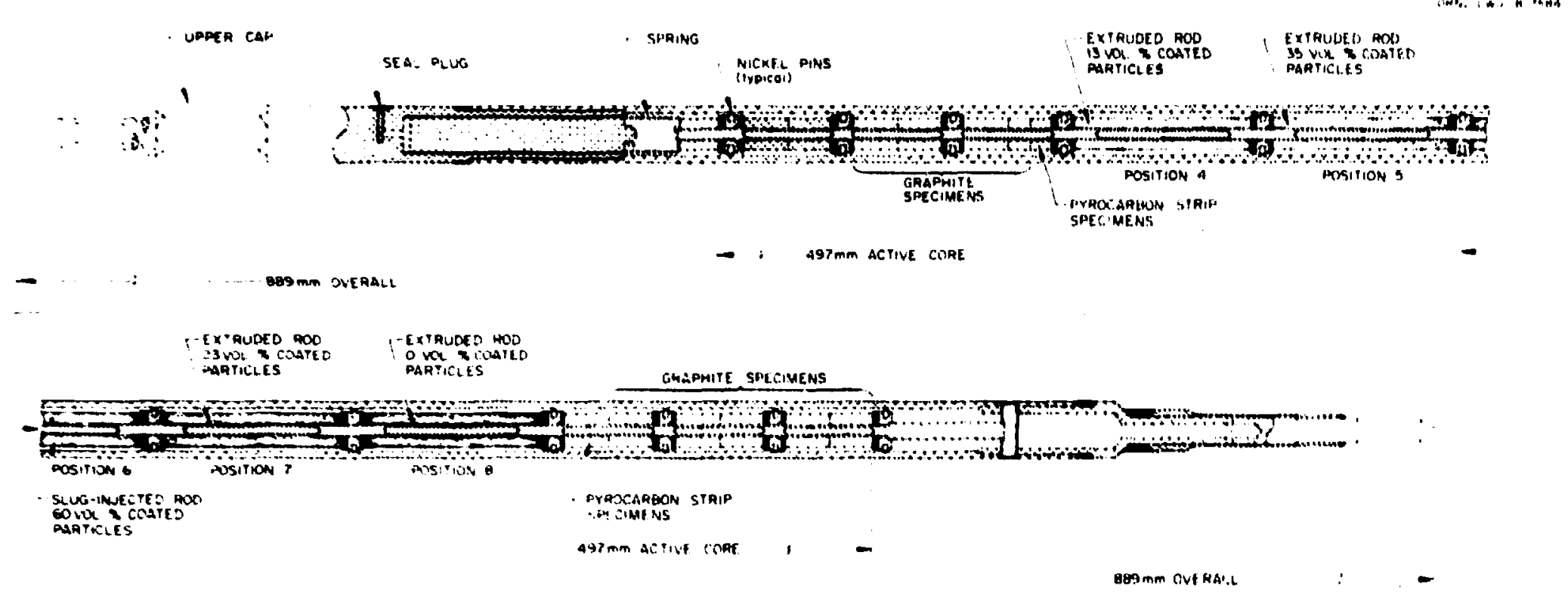

Fig. 4. Target capsule typical of HT-20, $-21,-22$, and -2.3 that contained slug-injected und extruded simulated fuel rods for thermal transport and expansion propeity decerminations. 


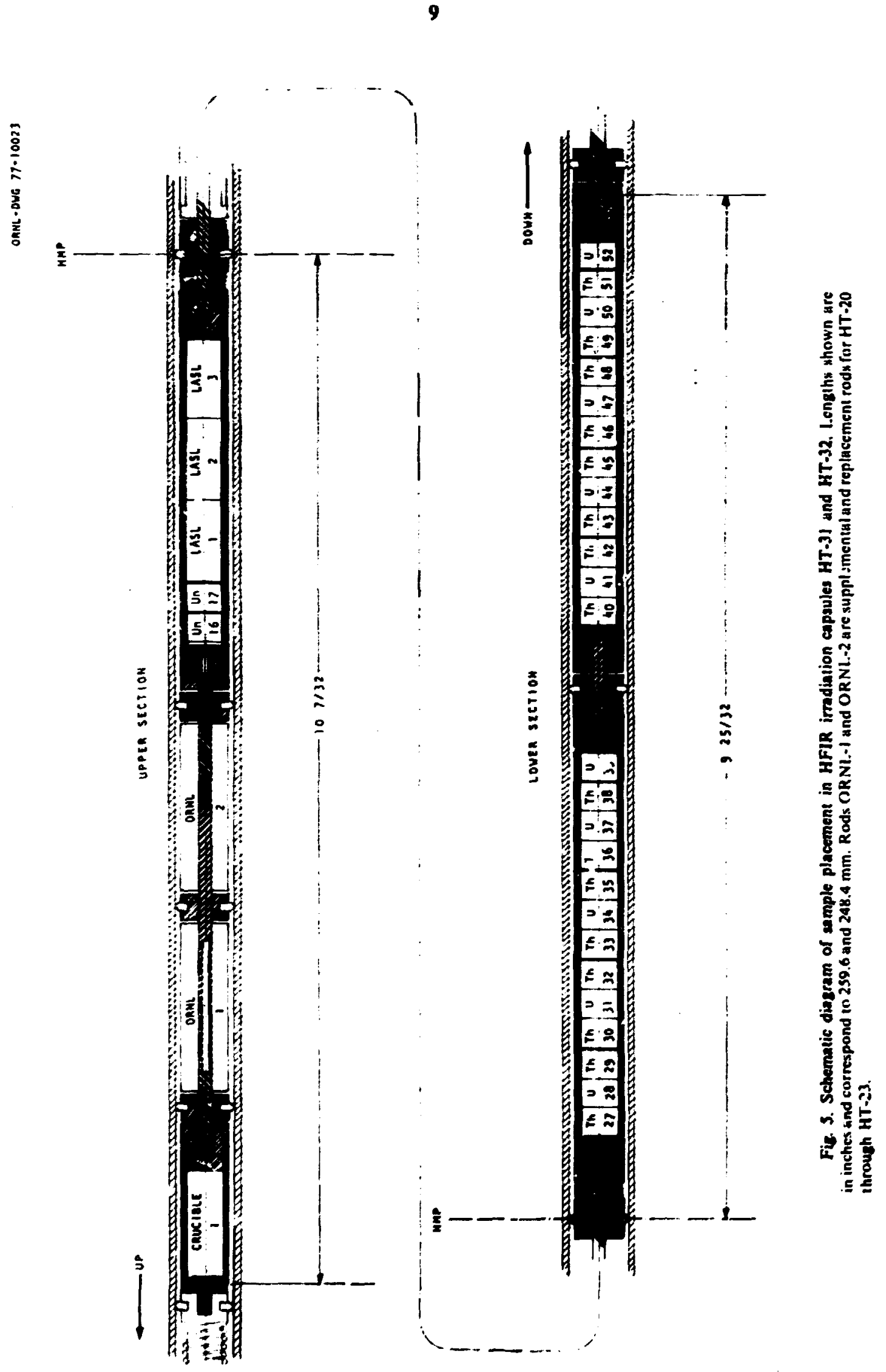


Table 2. Operatiag historie for target capoules that contained simulated fuel rods for therenal uransport and expasion property messuremers

\begin{tabular}{|c|c|c|c|c|c|c|c|c|}
\hline \multirow{2}{*}{$\begin{array}{l}\text { Tarke: } \\
\text { oprule }\end{array}$} & \multirow{2}{*}{ Faciluty } & \multirow{2}{*}{$\begin{array}{l}\text { HFlk } \\
\text { fuel } \\
\text { cycle }\end{array}$} & \multicolumn{2}{|c|}{ Begn } & \multicolumn{2}{|c|}{ End } & \multicolumn{2}{|c|}{ Irradiation $(\mathrm{hr})^{\alpha}$} \\
\hline & & & Time & Daie & Time & Date & Duriny cycle & Aciumubted \\
\hline HT-20 & $1 \because-7$ & 518 & 1416 & $6: 28: 74$ & 13411 & $7: 21: 74$ & 551.52 & 551.52 \\
\hline \multirow[t]{6}{*}{ HT 21} & $1-2$ & 1119 & 1842 & $7 / 22 / 74$ & 0400 & $8 / 15 / 74$ & 546.88 & 546.88 \\
\hline & & III & 175? & $B / 15 / 74$ & 20,12 & $9 / 4174$ & 549.610 & 1096.48 \\
\hline & & II & 1036 & $9: 12 ; 74$ & 0736 & $10 / 5: 74$ & 548.86 & 1645.36 \\
\hline & & 112 & 0525 & $16 / 6 / 74$ & 0218 & $16 / 31 / 74$ & 547.20 & 2192.56 \\
\hline & & 113 & 0318 & $11 / 1 ! 74$ & $1(1) 24$ & $11 / 21 / 74$ & 558.70 & 2751.26 \\
\hline & & 114 & 1332 & $11,25 / 74$ & $049 \sqrt{1}$ & $12: 18 / 74$ & 54.70 & 3292.96 \\
\hline \multirow[t]{4}{*}{ IIT-22 } & $1-7$ & 109 & 1842 & $7 / 22 ! 74$ & (144)10 & $8 / 15 / 74$ & 546.88 & 546.88 \\
\hline & & 111 & 1707 & $8 / 15 / 74$ & 2012 & $9 / 9 / 74$ & 549.60 & 11966.48 \\
\hline & & 111 & 1030 & $9 / 12 / 74$ & 0736 & $10 ; 5 / 74$ & 54888 & 1645.36 \\
\hline & & 112 & 0525 & $10 / 6 / 7$ & 0218 & $10 / 31 / 74$ & 547.20 & 2192.56 \\
\hline \multirow[t]{2}{*}{ IIT-23 } & $A-3$ & 111 & 1030 & $9 / 12 / 74$ & 0736 & $10 / 5 / 74$ & 548.88 & 548.88 \\
\hline & & 112 & 0525 & $10 / 6 / 74$ & 11218 & $10 / 31 / 74$ & 547.20 & 1096.08 \\
\hline \multirow[t]{4}{*}{ HT-3I } & (;-5 & 130 & 1732 & $3 / 14 / 76$ & 2354 & $4 / 6 ! 76$ & 557.76 & 557.76 \\
\hline & & 131 & 2124 & $4 / 7 / 76$ & 2312 & $4 / 30 / 76$ & $\because \div 48$ & 1119.24 \\
\hline & & 132 & 2142 & $5 i: / 76$ & $(1800)$ & $5 i^{9}=16$ & $484 \ldots$ & 1593.84 \\
\hline & & 133 & 2211 & $5 / 23 / 76$ & 1240 & 6. $16 / 70$ & 546.72 & 2146.56 \\
\hline \multirow[t]{4}{*}{ HT-32 } & C-5 & 140 & 1900 & $11 / 15 / 76$ & 0400 & $2 / 14 / 76$ & 577.011 & 577.60 \\
\hline & & i4I & 1711 & $12 / 15 / 76$ & 0115 & 191,77 & 568.07 & 1145.177 \\
\hline & & 142 & 2030 & $1 / 10 / 77$ & 20000 & $2,3 / 77$ & 576.50 & 1721.57 \\
\hline & & 143 & 1831) & $2 / 5 / 77$ & $2(M) 0$ & $\therefore 1: 77$ & 587.50 & $231,9.017$ \\
\hline
\end{tabular}

IIradiation time is given in aivivalent hours at I(M) MW.

Table 3. Fast and thermal Auences for simulated fued rods imadiated in the target repion of bIflk

\begin{tabular}{|c|c|c|c|c|c|c|c|c|c|c|c|c|c|}
\hline \multirow{3}{*}{ Specinien } & \multirow{3}{*}{$\begin{array}{c}\text { Distance } \\
(\mathrm{mm})\end{array}$} & \multicolumn{10}{|c|}{ Thermal $^{b}$ and fast thuence ineutrons $/ \mathrm{m}^{2}$, } & \multirow{2}{*}{\multicolumn{2}{|c|}{ HIT.32 }} \\
\hline & & \multicolumn{2}{|c|}{ HT-2n } & \multicolumn{2}{|c|}{ HT-2I } & \multicolumn{2}{|c|}{ HT-22 } & \multicolumn{2}{|c|}{ UT -23 } & \multicolumn{2}{|c|}{ HT-31 } & & \\
\hline & & Therinal & liast & Thermal & Fist & Thermal & Finst & Thermal & Fast & Thermal & Fast & Therma! & Fast \\
\hline 4.8 & 114.3 & 4.63 & 2.113 & 2.76 & 12.199 & 1.84 & 8.115 & 9.19 & 4.0 .3 & & & & \\
\hline 5.7 & 57.2 & 5.18 & 2.26 & 3.15 & $1 ? .51$ & 2.10 & 9.111 & 10.50 & $4.5 i 1$ & & & & \\
\hline$\sigma^{6}$ & 0 & 5.62 & 2.34 & 3.35 & $13.9 \%$ & 2.23 & 9.31 & 11.17 & 4.66 & & & & \\
\hline ORNL.-1 $f$ & $196 . \%$ & & & & & & & & & 1.36 & 5.66 & & \\
\hline ORNL.-2 ${ }^{d}$ & $13^{6} .7$ & & & & & & & & & $3.76^{\mathrm{NJ}}$ & $16.30^{\circ}$ & & \\
\hline ORNL,-I ${ }^{f}$ & 196.9 & & & & & & & & & & & 1.46 & 6.119 \\
\hline OKNI.-2 & 139.7 & & & & & & & & & & & $12.29^{\circ}$ & $12.39^{\circ}$ \\
\hline
\end{tabular}

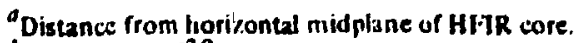

$b_{V}: 6,6 \times 11^{-2 n}$ J $(10.414 \mathrm{eV})$.

ci: . 28.8 is (1).18 A(ev).

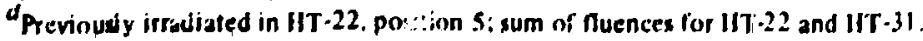

Previuusy irradiated in HT.23, position 7; sum of huences for HT.23 and HT.32.

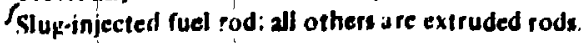


The retrieval of thi: supplementary and replacement rods from HT-31 and HT-32 was not much better: two rod; were rscovered intact, and both slug-injected rods were broken. The condition of all of the rods from the fiv: HT-capsules are listed in Table 4 . After a period of about one month after removal from HFIR, the activity of most of the simulated fuel rods was low enough to permit removal from the hot cells for the experimental determinations of the thermal transport and expansion properties. The extruded specimen from HT-32 was too hot to permit measurement outside a controlled zone.

Table 4. Condition of fuel rod specineans thet removal from capsules HT-20, -21, -22,-23,-31, and -32

\begin{tabular}{|c|c|c|c|c|c|c|}
\hline \multirow{2}{*}{$\begin{array}{c}\text { No. of HFTR } \\
\text { cyctes }\end{array}$} & \multirow{2}{*}{ Capoule } & \multicolumn{5}{|c|}{ Nominal particle loading ( $\mathrm{rol} \%$ ) } \\
\hline & & $\mathbf{0}$ & 13 & 23 & 35 & 58 \\
\hline 1 & HT -20 & $\mathbf{O K}$ & $\mathbf{O K}$ & $\mathbf{O K}$ & OK & Broken \\
\hline 2 & HT -23 & OK & $\mathbf{O K}$ & OK & OK & Broken \\
\hline 4 & $H T-22$ & OK & OK & $\mathbf{O K}$ & $\mathbf{O K}$ & Broken \\
\hline 6 & $H T-21$ & $\mathbf{O K}$ & $\mathbf{O K}$ & Broken & Broken & Broken \\
\hline 4 & $H T-3 i^{b}$ & & & & $O K^{c}$ & Broken \\
\hline 4 & $H T \cdot 32^{\bar{v}}$ & & & OK & & Broken \\
\hline
\end{tabular}

"Some data obtainable since fuel rod was broken in two pieces.

bone of the purposes of HT 31 and HT-32 was to provide irradiated slug-injected specimens, but these specimens were broken sither during irradiation or capsule disassembly.

SSame rod previously irradiateci in HT-22, position 5.

${ }^{a}$ Same rod previously irradiated in HT-23, position 7. Specimen too radicactive for neasurement after irradiation.

\section{RESULTS ON UNIRRADIATED SPECIMENS}

\section{Coefficient of Thermal Expansion}

Figure 6 shows that the CTE of each unirradiated bunded-bed fuel rod increased smoothly with increasing temperature. Each curve was fitted with a second-degree polynomial with the coefficients given in Table 5. Figure 7 shows that the CTE at 298 and $973 \mathrm{~K}$ increased linearly with particle loading for the unirradiated materials. This indicates that a simple mixirig law describes the effect of coated particles on the CTE of a fuel rod. Th.e fact that the slug-injected 58 -vol \% sample showes a CTE in accord "with those " 1 the extruded samples might be considered s. tprising in view of its low matrix density and different matrix composition. Because porosity variation alone will not change the $C^{2} E_{\text {, }}$ the larije density diff. -ences between the slug-injected and extruded materials had no effect on the CTE. The degree of graphitization does, however, influenre CTE: after fabrication heat treatment. the ratios of graphitic carbon to nongraphitic carbon for the extruded matrix and for the injected matrix were about 2 and 1.5 respectively. The matrices were, therefore, actually qu ite similar. However. because the particles in the specimen with 58-vol \% loading were in a closely packed a rray, the observed thermal expansion was essentially that of the particles and was only slightly affected by the matrix. Therefore, a significant conclusion drawn from the 58-vol \% sample data is that the apparent room temperature (TF. of these coated particles was less than $4 \times 10^{-6} \cdot \mathrm{K}^{-1}$. 


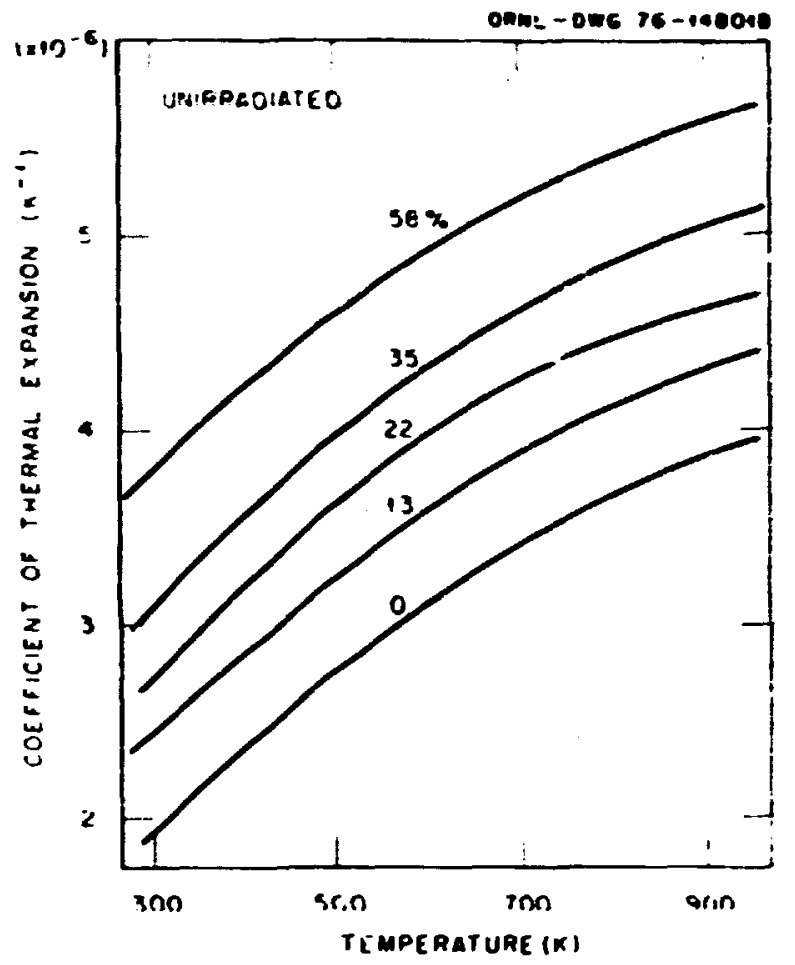

Fig. 6. The CTE of unirradiated simulated fuc: :eds as functions of temperature.

Table S. Coefficient of thermal expanion (CTE) of simulated fuct rods

\begin{tabular}{|c|c|c|c|c|c|c|}
\hline \multirow{2}{*}{$\begin{array}{l}\text { Purticle kadinga } \\
\text { |vol ril }\end{array}$} & \multirow{2}{*}{ 1. $11^{25}$ neutrons/ $\mathrm{m}^{2}$, } & \multicolumn{3}{|c|}{$\operatorname{Cry}:\left(K^{-1}, \times 10^{6}=A+B T+C T^{2}\right.$} & \multicolumn{2}{|c|}{$\left.\operatorname{ct}:(x) 10^{-6} \cdot h^{-1}\right)$} \\
\hline & & $\boldsymbol{A}$ & is & $C \times 10^{6}$ & $293 \mathrm{~K}$ & $973 \mathrm{~F}$ \\
\hline 0 & $" 1$ & 0.272 & 0.00628 & 2.58 & 1.92 & 3.95 \\
\hline 0 & 2.112 & 0.012 & 0.00545 & -1.41 & 1.48 & 3.95 \\
\hline 0 & $; .13$ & 0.029 & 0.001502 & 0.78 & 1.45 & 4.17 \\
\hline n & 8.115 & 0.545 & 0.100790 & -3.36 & 1.51 & 3.96 \\
\hline 0 & 12.1 & 0.221 & 0.00744 & -3.31 & 1.70 & 3.88 \\
\hline 13 & 0 & 0.746 & 0.00627 & -2.59 & 2.38 & 4.39 \\
\hline 13 & 2.02 & -0.152 & 0.00670 & -2.46 & 1.63 & 4.04 \\
\hline 13 & 4.113 & 0.076 & 0.00502 & -0.96 & 1.49 & 4.00 \\
\hline 13 & x.11.5 & $\ldots .549$ & 0.00736 & -2.97 & 1.38 & 3.80 \\
\hline 13 & 12.1 & -0.513 & 0.00763 & -3.43 & 1.40 & 3.60 \\
\hline 22 & $n$ & 0.761 & 0.00736 & -3.41 & 2.66 & 4.69 \\
\hline 22 & 2.26 & 0.451 & 0.00496 & 1.34 & 1.81 & 4.01 \\
\hline 22 & 4.5 & -0.387 & 0.00675 & 2.60 & 1.39 & 3.72 \\
\hline 22 & $9.1)$ & -0.687 & 0.00704 & 2.70 & 1.17 & 3.60 \\
\hline 35 & $\mathbf{0}$ & 1.188 & 0.00708 & -3.11 & 3.02 & 5.13 \\
\hline 35 & 2.26 & 0.155 & 0.00650 & -2.66 & 1.86 & 3.96 \\
\hline 35 & 4.5 & 0.145 & 0.00469 & 0.36 & 1.46 & 3.81 \\
\hline 58 & 10 & 2.038 & 0.00657 & .2 .94 & 3.74 & 5.66 \\
\hline
\end{tabular}




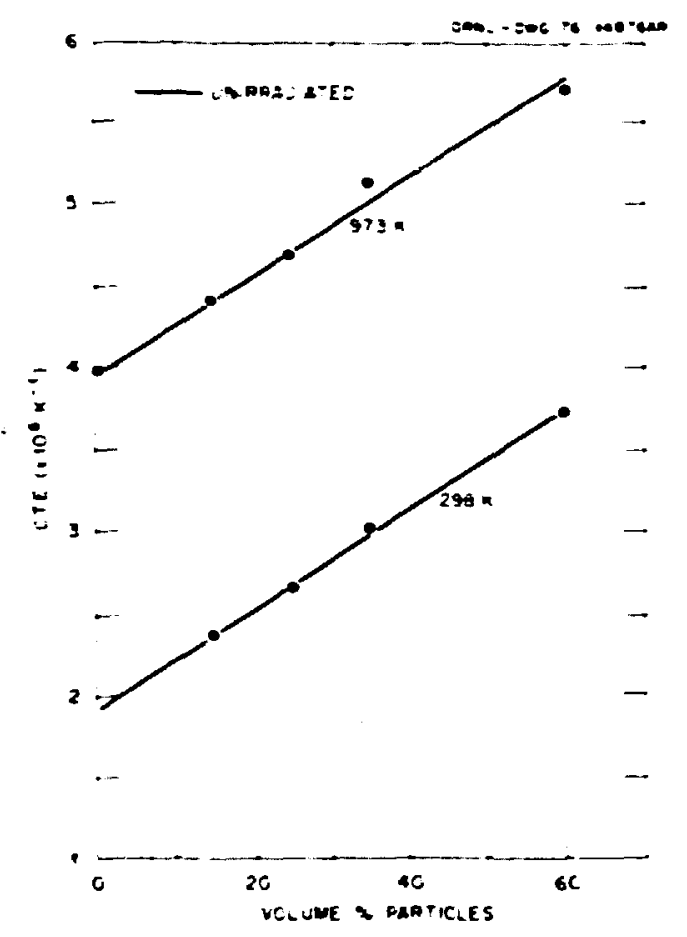

Fig. 7. The CTE is volume percent particle loading at 298 and $\$ 73 \mathrm{~K}$ showing the uniform increase with particke landing.

\section{Electrical Resistivity and Scebsck Coelficient}

Figure $\mathbf{S}$ shous the $\rho$ and $S$ of all unirradiated materials as functions of temperature. Electrical resistivity of irradiated and unirraciated materials are given in Table 6 , and smoothed $\rho$ values are given in Table 7. The $\rho$ of each specimen decreased smoothly u ith increasing temperature in a manner similar to isotropic graphites. At a constant temperature. the $\rho$ increased smoothlv with increasing particle loading for the extruded material. but tne of the slug-injected specimen with 58\%; loading was much higher than that of the extruded specimens. This was partially duc to the lower density matrix of the slug-injected specimen.

\section{Thermal Conductivity}

The $\lambda$ results from measurements on unirradiated simulated fuel elements are shown in fig. 9 as : function of temperature, and smoothed values are given in Table 8 . The natriv material of the extruded specimens had the highest $\lambda$. The addition of particles lowered $\lambda$ at all temperatures; this is illustrated in Fig. 10 for $T=400 \mathrm{~K}$. This smooth decrease of $\lambda$ with increasing particle loading is similar to the decrease in elecirical conductivity, $\sigma=\rho$ '. which is also shown. Figure 9 also shows data obtained hy Johnson:" on two slug-injected specimens. One of these had $58-v 0 l$; fuel particles and the other had 35-vol ii fuel parficles with 22-vol \% shim. Johnsor:'s Jata ire iil general agreenent with the extrapolation of the present results on an unirradiated slug-injecied specimen.

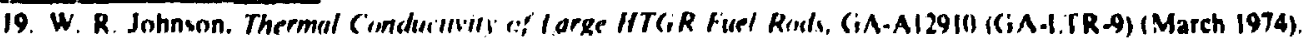




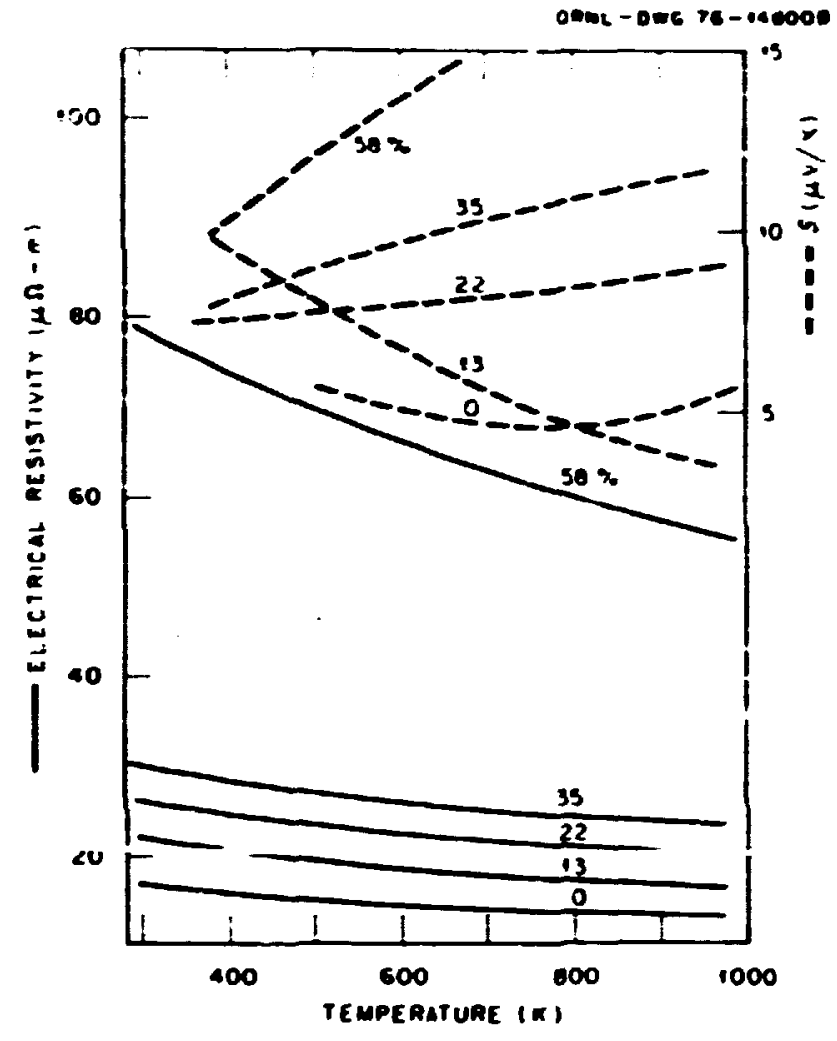

Fig. 8. The $p$ and $S$ of unirradiated specimuns vs temperature.

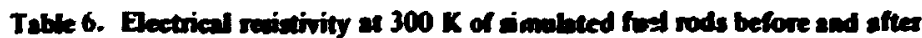
indiation in FIFtR in microhm meters

\begin{tabular}{|c|c|c|c|c|c|}
\hline \multirow{2}{*}{$\begin{array}{l}\text { Particle bading } \\
\text { (vol \%) }\end{array}$} & \multicolumn{5}{|c|}{ Number of cycles" } \\
\hline & 0 & 1 & 2 & 4 & 6 \\
\hline$n$ & 17.20 & 26.82 & 28.81 & 39.25 & 67.21 \\
\hline 13 & 21.90 & 32.31 & 34.58 & $\$ 3.74$ & 67.04 \\
\hline 22 & 26.59 & 37.14 & 39.61 & 51.08 & 90.76 \\
\hline 35 & 30.07 & 38.75 & 40.15 & 5124 & $b$ \\
\hline 58 & 79.11 & 95.50 & $b$ & $b$ & $b$ \\
\hline
\end{tabular}

${ }^{a}$ Fach cycle in HITR equivilent to between $2.0 \times 10^{25}$ to $2.34 \times 10^{25}$ neutrona/ $\mathrm{m}^{2}$ depending on poxition. Exact values are kiven in Appendix $A$.

broken during irradiation or during capale dimaembly. 


\begin{tabular}{|c|c|c|c|c|c|c|c|c|c|}
\hline \multirow{2}{*}{ 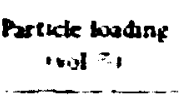 } & \multirow{2}{*}{$\begin{array}{l}\text { Neuzron nuence } \\
\text { 1. In }\end{array}$} & \multicolumn{7}{|c|}{ Temperature $1 \mathrm{~K}$, } & \multirow[b]{2}{*}{1000} \\
\hline & & in: & thet & $\sin$ & $\cos$ & 700 & $\sin$ & 909 & \\
\hline$\because$ & $\because$ & $\because \because$ & If.:! & 152 & 145 & $1+.0$ & 130 & 134 & 13.3 \\
\hline$"$ & $2 \dot{0}=$ & $2 n o$ & $2+1$ & 220 & 202 & 18.6 & 17. & 16.5 & 15.9 \\
\hline ") & 413 & $36 \mathrm{~s}$ & \pm 90 & 27. & 28.1 & 224 & 208 & 19.2 & $1: 0$ \\
\hline$n$ & 81,5 & is 2 & is : & 334 & 310 & $29 . \%$ & 27.2 & 25.6 & $2+.2$ \\
\hline is & $12(n)$ & 67.2 & 6519 & sen & sn. 2 & $53.10^{\circ}$ & 50.1 & 47.4 & 45.0 \\
\hline i: & $\because$ & 22.2 & & & & & & & \\
\hline $1 \vdots$ & 202 & 32.1 & $\therefore 4: 2$ & 20.7 & $2+5$ & 22.7 & 21.2 & 20.1 & 19.3 \\
\hline 13 & 4.15 & is 6 & $\because: 4$ & $2 \times 7$ & 26.4 & 24.0 & 33.1 & 22.0 & \\
\hline $1:$ & 8.15 & $4: 7$ & \&s. & 37.4 & $3+8$ & 324 & 311.2 & 28.5 & 26.9 \\
\hline 13 & 12.19 & 0711 & 016 & 570 & 52.8 & 49.2 & 460 & 43.0 & 40.4 \\
\hline 22 & " & $30 \vdots$ & 2511 & 23.8 & 228 & 21.9 & 21.2 & 30.7 & 20.3 \\
\hline 22 & 2.20 & is 4 & $3:$ & 3014 & 28.11 & 26.11 & 24.2 & 22.9 & 21.8 \\
\hline 22 & $+5 n$ & iyt. & 55 & $\$ 2.6$ & 29.8 & 27.5 & 25.6 & 23.8 & 22.5 \\
\hline 22 & 9.11 & SI 1 & th 7 & +5.6 & 39.8 & is 9 & 343 & 32.10 & 29.8 \\
\hline 22 & 135 & $90 \mathrm{~h}$ & & & & & & & \\
\hline is & " & sinn & Ix.5 & $2 ? 1$ & 259 & 25.11 & 24.3 & 23.7 & 234 \\
\hline 35 & $\therefore 2 n$ & $3 \times 7$ & & & & & & & \\
\hline 35 & $+5 n$ & Ii1 & inn & $33 k$ & 30.8 & $28+$ & $2 \pi .3$ & 24.f. & 23.5 \\
\hline is & 9.11 & 512 & $+1=$ & $+2+$ & 34.3 & ing.e & 34.11 & 33.4 & 32.7 \\
\hline 35 & 135 & & & & & & & & \\
\hline$=x$ & $m$ & ins 5 & 74.1 & 711.1 & & 0.3 .1 & 611.1 & 57.5 & 5S 3 \\
\hline
\end{tabular}

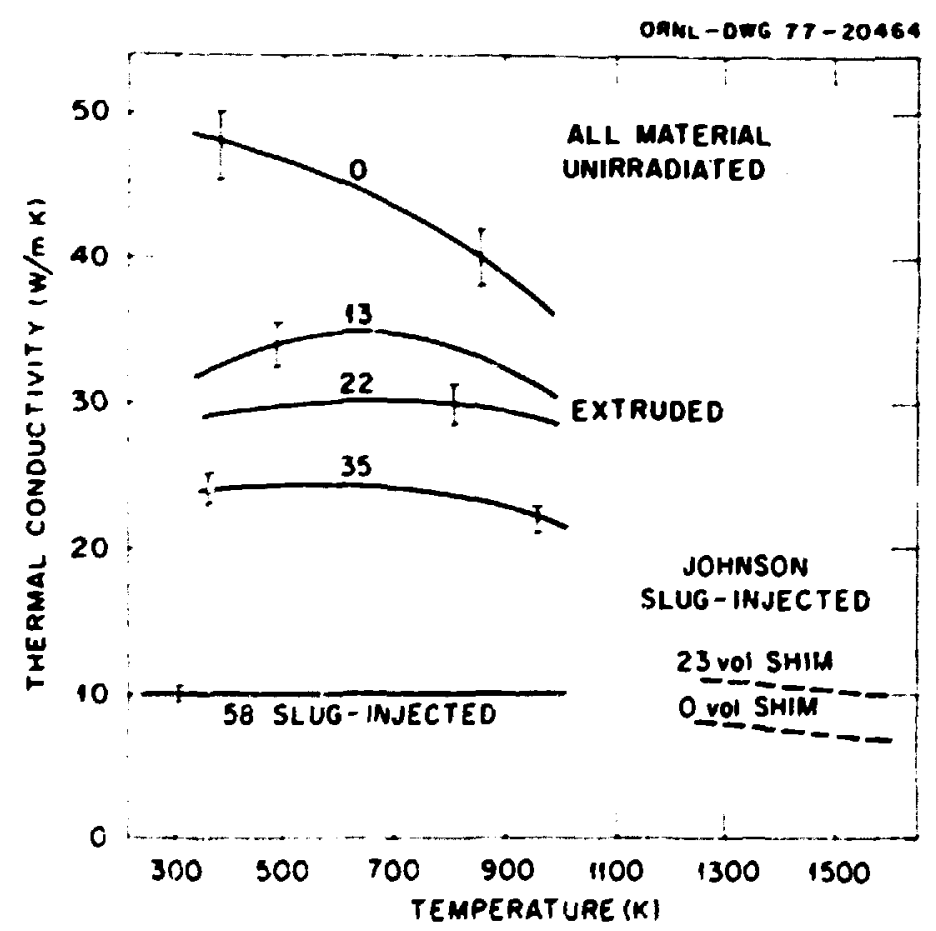

Fig. 9. The A of unirradiated simulated fuel rods vs lemperature for five loadings. High-lemperature data f-om Johnson" des shoun for compasioun. 


\begin{tabular}{|c|c|c|c|c|c|c|c|c|}
\hline \multirow{2}{*}{ 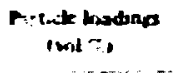 } & \multirow{2}{*}{ 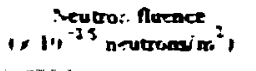 } & \multicolumn{7}{|c|}{ 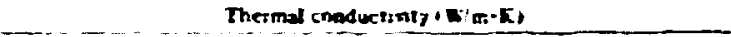 } \\
\hline & & $4 \%$ & $\sin$ & sods & $\mathrm{nrin}$ & ares, & and & $\operatorname{ltm} 5$ \\
\hline$\because$ & $" ;$ & 675 & $47:$ & at $:$ & Ata & $4: !$ & $39 \pi$ & 393 \\
\hline$r_{1}$ & 212 & 414 & +23 & $4 ; 3$ & 43.1 & 425 & $\$ 16$ & 3311 \\
\hline 6 & $41:$ & In \& & 342 & $39 !$ & $3+\infty$ & 370 & $39 ?$ & \\
\hline$\cdot$ & 805 & 199 & 212 & 215 & 22 & 21.7 & 209 & $2 x, t$ \\
\hline$a$ & $12 \mathrm{rs}$ & 9.6 & In.1 & 10.5 & 10.4 & 196 & 10.4 & 10.5 \\
\hline II & : & 334 & 365 & 352 & 349 & 340 & 32.2 & H) ; \\
\hline Ij & $2 m 2$ & $12 *$ & $4 !$ & 245 & 34.2 & 336 & 323 & 30.4 \\
\hline is & 4.63 & 292 & $\$ 97$ & 299 & 297 & 29.3 & $2 \pi n$ & $2 n .1$ \\
\hline Ij & 8.05 & IR.t. & 19.4 & 3115 & $21 n$ & 210 & 35 & 19.7 \\
\hline 13 & $12: 9$ & 112 & 128 & 125 & 12.7 & 125 & $: 210$ & IIn \\
\hline 22 & an & 29.5 & $3 n+1$ & 30.2 & $3 y+1$ & 30.2 & 296 & 292 \\
\hline 22 & 226 & 246 & 300 & 303 & 3,5 & 296 & 24 I & $26 . b$ \\
\hline 22 & +50 & $2 \mathrm{I} 1$ & 287 & $28 \mathrm{~B}$ & $2 \mathrm{H}_{0}$ & 2R.0 & 27.1 & 26.0 \\
\hline 22 & 96 & $19:$ & $18 \mathrm{~A}$ & 122 & {$[9: 2$} & 189 & I4; & 17.6 \\
\hline 22 & 135 & & & & & & & \\
\hline is & $n$ & 242 & 246 & 24.7 & 24.2 & 23.3 & 220 & \\
\hline 35 & 220 & $2 \pi 6$ & 29.11 & $3 \cdot n$ & 102 & 29.6 & $2 \times 0$ & 3h 0 \\
\hline 39 & +50 & 222 & 246 & $25 h$ & $2 h .7$ & 27.8 & $: 2.9$ & 285 \\
\hline 35 & 9.0 & 12.9 & 134 & 142 & 14.4 & 140 & 13.0 & 115 \\
\hline 35 & 13.5 & & & & & & & \\
\hline 58 & n & 10.2 & (I) $\mathrm{B}$ & 11.2 & 11.3 & 11.2 & In. & 10.4 \\
\hline 58 & 234 & 118 & 12 & & & & & \\
\hline $5 n^{*}$ & 16 & $s$ & $s$ & & & & & \\
\hline $35^{\circ}$ & D & 34.3 & 374 & 353 & & & & \\
\hline
\end{tabular}

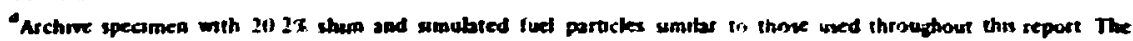
motrix c. I hus specamen was fabnoted from the some matenal as the ofher sive tnjected amples

"Linuraduted specamen that has been paphitized at $291 \% k$.

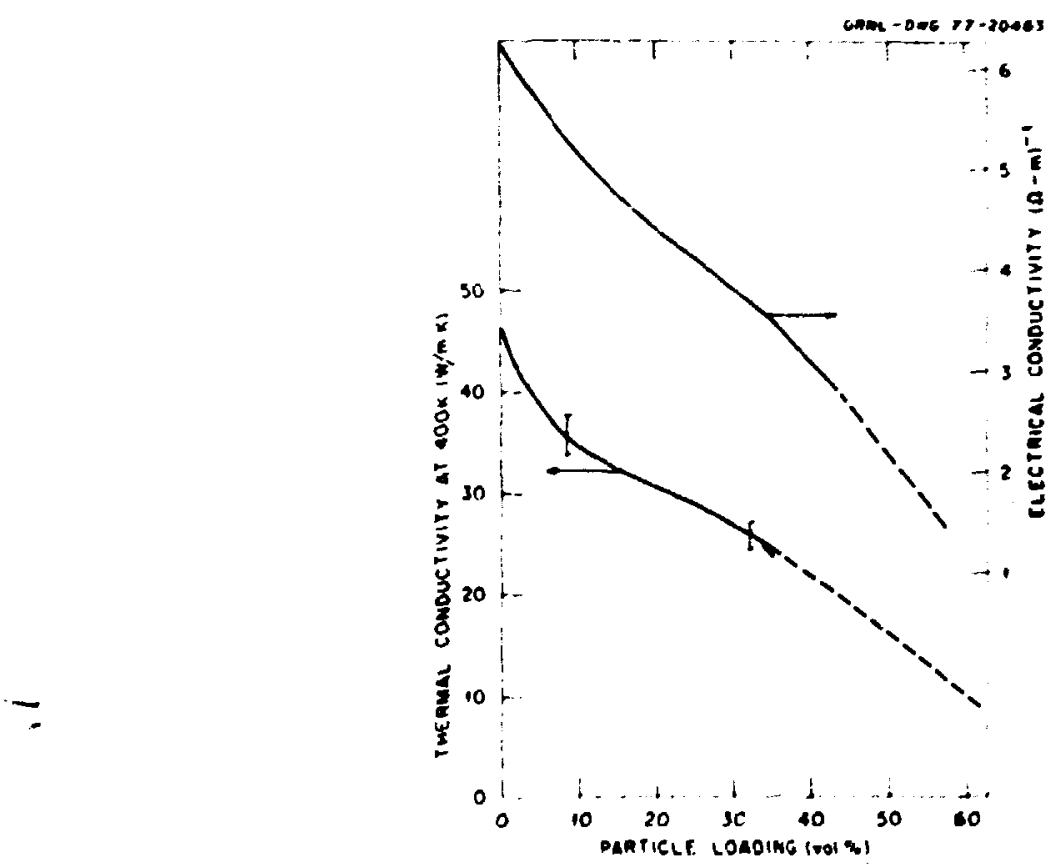

Fis. 10. Thermal (at $40 \mathrm{~K}$ ) and electrical (at $300 \mathrm{~K}$ ) conductivities of unirnadiated simulated fuet rods showing the snooth decrease with panicle loading and the similar behavior of $a$ and $A$ 


\section{RESLLTS ON IRRADIATED SPECIMENS}

\section{Visual}

With anc exception. al! extrudef specimens in this test suntved neutron irradiation. The one exception was the specimen with $35-1$ et "; particis which had gone to $13.5 \times 10^{\circ}$ neutrons $\mathrm{m}^{\prime}$ IF $>28 . x$ is, ar 6 cyetes in HIIR.

In conts.'st. all slug-injeted specimens uere ven fragile and fell apart either during irrel ation or during caret al rentine handling. This is vimilar to the behaviur observed by others" on shug-injected specimens with vang shim content.

\section{Volume}

The propeties of tixe simulated fuel rods studied in this experiment changed significantly with neutron irradiatıon. Tiue volunetric ctiangex as a function of acutron fluence are show $n$ in Fig. II. All specimens stumed an initial decrease in volume with increasing fluence up to about $4 \times 10^{-1}$ neutrons $\mathrm{m}^{2}$. Above that fluenie. this trend retersed. and they reached their initial volume between $9 \times 10^{\circ}$ and $12 \times 10^{\circ}$ neutron, $m^{\circ}$.

\section{Conftwiont of Thromal Frgantion}

I.on-order poty nomials wt ich expres the CTE results obtained on the simulated fuel rods are given in Table 5 . In additur., values for CTE at 298 and $973 \mathrm{~K}$ are labulated. As was shown in Fig. ? Ior the un.rradiated samples. the CTEv at 298 atud $973 \mathrm{~K}$ were almost directhy proportional to the particle content Houeter. this behavior changed after the initial irradeation cycle $1 \sim 2 \times 10^{*:}$ neutrons $a^{3}$ ). and the (TF. became almost independent of particle loading for all exiruded specinnens as shou $n$ in $F_{i g}$. I2. Although the broken slug-injected specimen containing $58-10$ ol $r_{i}$ particles was satistattory ior wme limitcd a measurements. . was too short for CTE determinations. and no CTE data wete obtained on the $58-1,0$; fading series after irradiation.

\section{Electrial Resistivity}

Ihe $p$ of all specilocn, uas measured at roum temperature following irradiation, and the results are $y: b: n$ in 1 able $G$ and plotted in Fig. 13. All extruded materials behaved similarly. The electrical

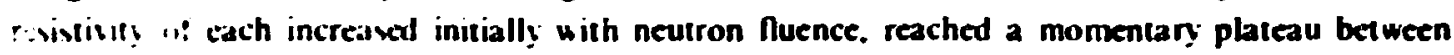
$3 \times 10^{\circ}$ and $4 \times 10^{\circ}$ neutrons $\mathrm{m}^{\circ}$. and then began another rapid increase with fluence. The positive deviations of $\rho$ abou c the relatively hat regions near $4 \times 10^{-*}$ neutrons $m^{\prime}$ coincided with the minima in the $V$. curves of rig. 9. The $p$ of the 58-vol $r$ loaded specimen from the slug-injection process increased unilormly with tluence and did not hase a short-term flat region similar to the onc noted in the extruded specimens. The o $1300 \mathrm{~K}$ ) of the specimens with 22 -and 35 -vol $\%$ particles and the $(300 \mathrm{~K})$ of the n- and 13-10l'; particles tended to merge at higher fluence. This rather interesting effect is apparent in Fig. 14, which shows p $1300 \mathrm{~K}$ ) versus particle loading after each reactor cycle. The 22- and 35-vol ' $;$ specimens had essentially the same $\rho$ after two cycles in HFIR whereas the 0- and I3-sol'; specimens had the same $p$ after six cycles. Measured values of pare given in Appendix A. and smootheal $\rho$ data lor all specimens are given in Table 4.

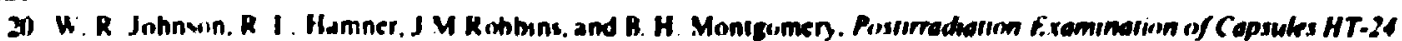
and II T.A. (BA.Al Haxh tocpermher 1975) 


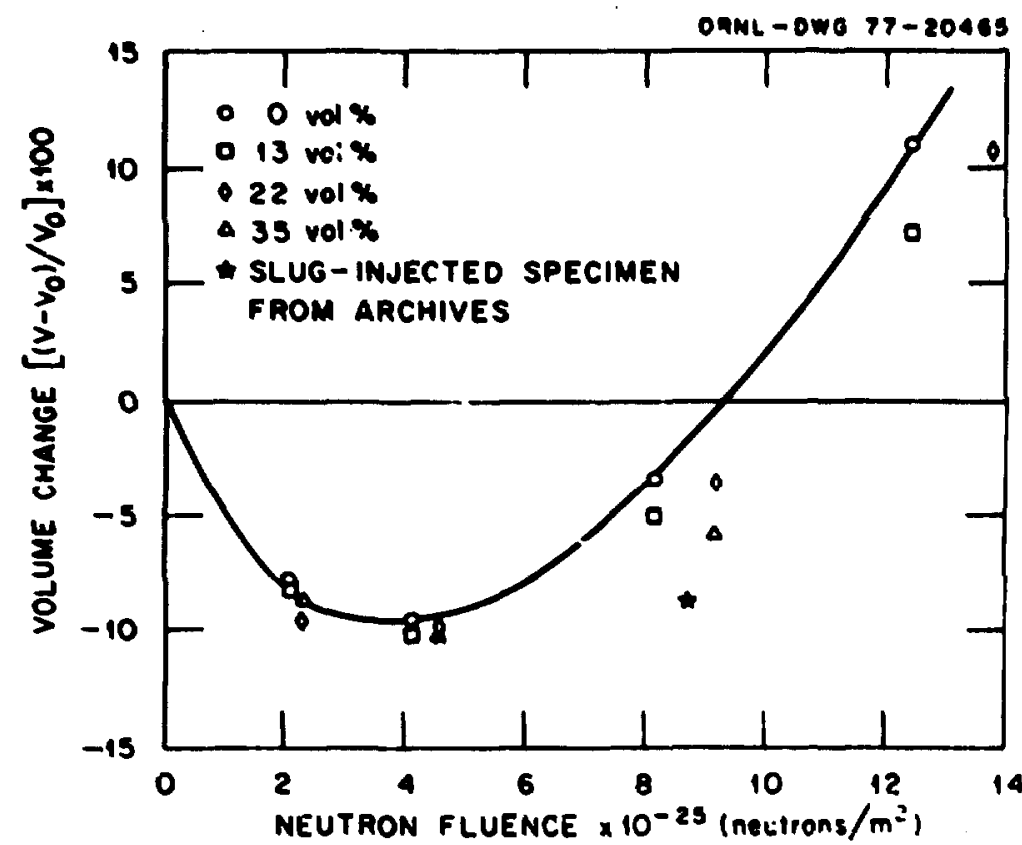

Ei. 11. Specimen volume change (at room temperature) vs fluence showing a mini

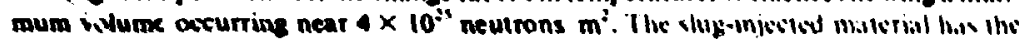

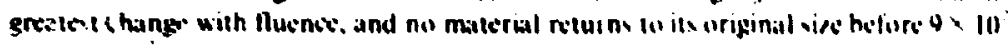
neutron, $m$

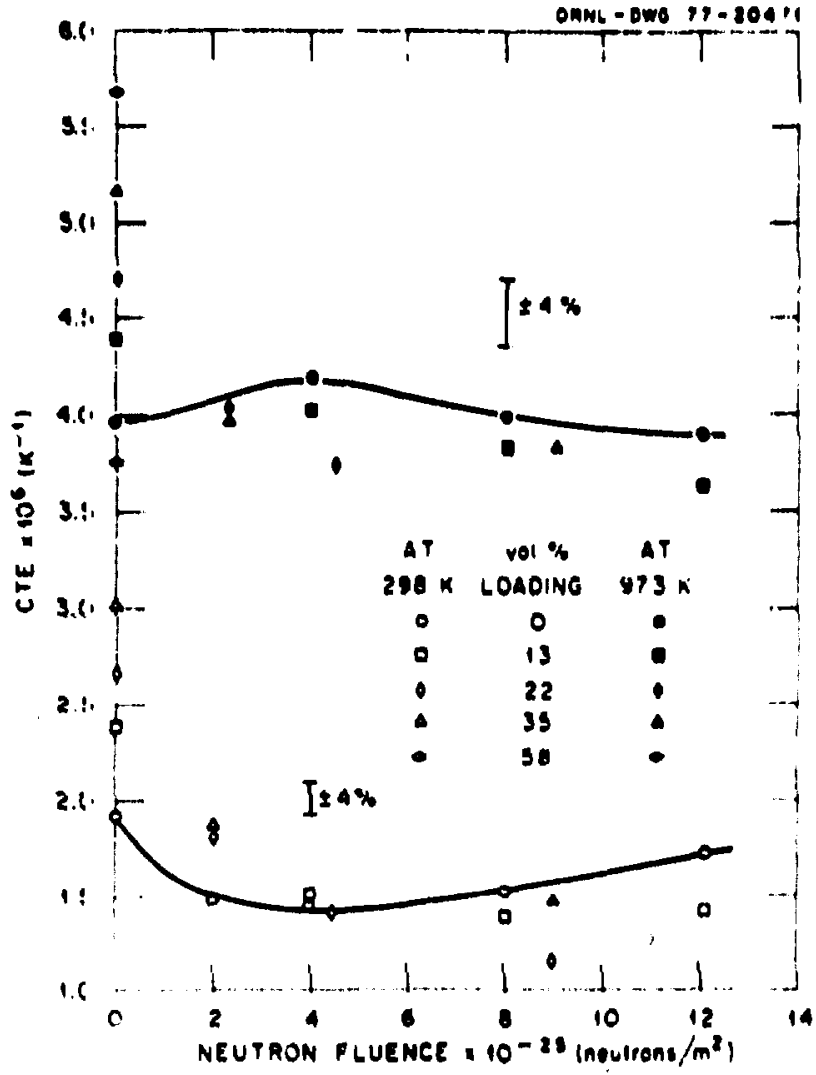

Fig. 12. Th. CTE of exIruded and alug-injecied apecimens va nuence showing the relative inaensiti ity to particie loading and neutron fluence after one cycle. Sullid lint's

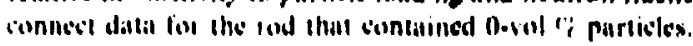




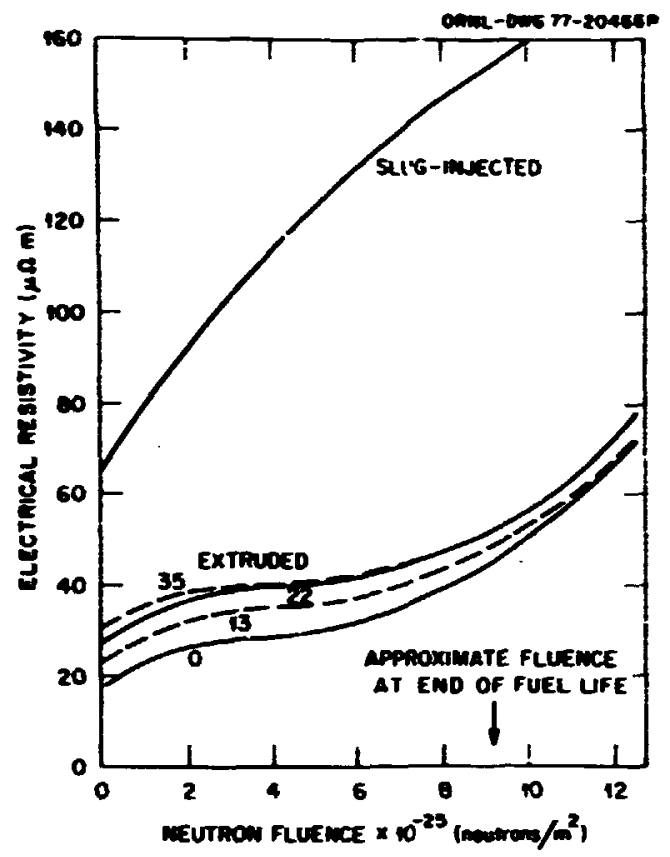

Fig. 13. The electrical resistivity at room temperature us neutron fluence for the simulated fuel rods shewing the phteau region observed in the exinded specinens.

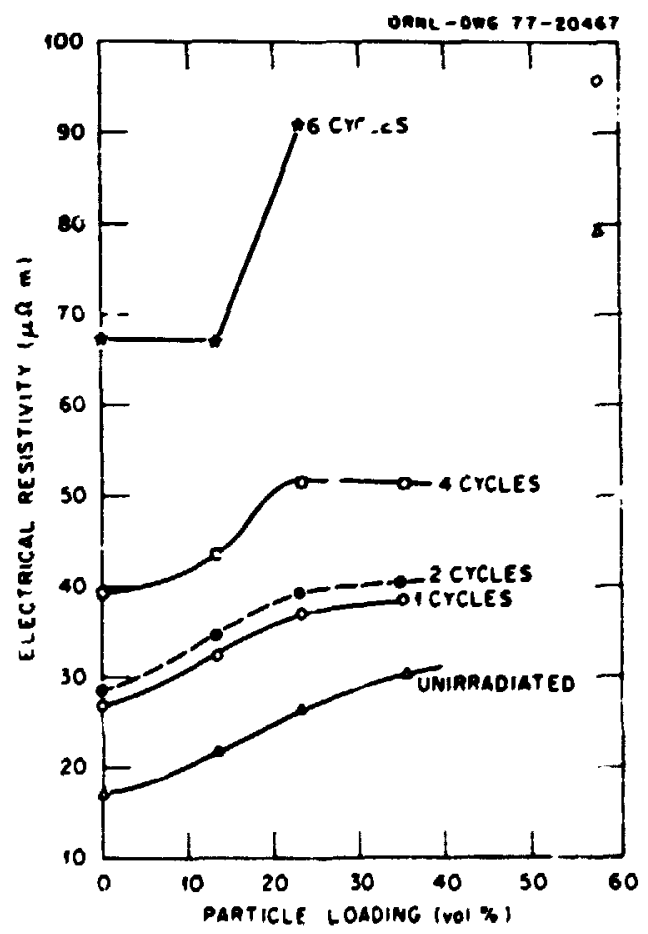

Fig. 14. The $p$ of simulated fuel rods for various reactor cycles vs particle loading. 


\begin{abstract}
Absolute Seebeck Coeficient
Al! Secteck coefficient data are given in Appendix A. With the exception of the unirradiated specimen with 13-iol $\%$ particles. the $S$ for a specific particle loading did not vary greatly with tenuperature. Therefore. 1 \& 5 shows the $\mathbf{S}$ data obtained at the lowest measurement temperature ( $\sim 390 \mathrm{~K}$ / versus neutron tluezce. All loadings had positive values for $\mathrm{S}$, which increased in magnitude with increasing fluence and then hegan decreasing at roughly the same fluence at which $\Delta V V_{0}$ minimized and $\rho$ plateaud.
\end{abstract}

\title{
Thermal Conductivity
}

All thermal conductivity results on the irradiated specimens are given in Appendix A, and smorthed values are presented in Table 8 . The initial effects of neutron irravation after one reactor cycle are shown in Fig. 16. The specimen fabricated using the slug-injection process still had the lowest $\lambda$, but it is about 10\%; higher than data obtained on the unirrediated specimen. The data for this specimen "were limi:ced in temperature range hecause the broken specimen was so short that measurements were revericted to the 1.TI., which has an upper limit of $400 \mathrm{~K}$.

The $\lambda$ of the extruded specimen with 35-vol \% particles actualiy iffereased during the first

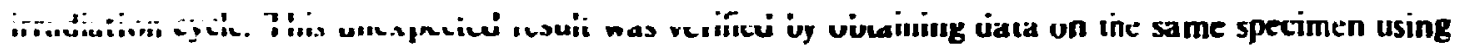
the I.TI. Results from the two techniques agreed to within $\pm 3 \%$. The $\lambda$ of the 22 - and $35-$ vol $\%$ specimens were nearly equicalent after one reactor cycle. This is reminiscent of the similar $\rho$ values of the two loadings after one cycle. The $\lambda$ of the 13 -vol $\%$ and the 22 -vol $\%$ specimens was almost unaffected by the first $2 \times 10^{\circ "}$ neutrons $m^{2}$ whereas the matrix material $\lambda(0$ vol \%) dropped by about $15 \%$.

Alt hough the $\lambda$ curses saried somewhat with temp: ature, the results at $400 \mathrm{~K}$ are representative, and these vere selected (1) compare the results at higher fluence." The smoothed values at $400 \mathrm{~K}$ from Table 8 are. therefore, show $n$ in Fig. 17 versus fluence. The specimen labeled "58 vol $c \%-20.2 \%$ Shim" was not an original part of this test but was obtained from a previous irradiation experiment. This specimen was listed as $\$ 14-4$ in Table \# 4 of Johnson et al. " One conclusion of Johnson et al." is that this specimen contained the superior shim tvr- of the many that they tested. The matrix material of the extruded specimen (0 vol $(;)$ had the :ighest $\lambda$ initially. This $\lambda$ decreased but had a plateau over a limited fluence range. This behav ior $i$. similar to that observed by Delle et al. ${ }^{4}$ on other carbonaceous matcrials. The $\lambda$ of the 13- and 22-tol $\%$ specimens remained essentially constant initially and then decreased smoothly with increasing tluence. The extruded specimen with 35-vol \% loading and the slug-injection specimen with $58-001 \%$ Inading had $\lambda$ that increased with fluence initially and then decreased heyond $3 \times 10^{\circ}$ or $4 \times 11^{\prime \prime}$ neutrons $\mathrm{m}^{2}$. The reason ior this behavior is discussed in a later section.

The $A$ value of $5 \mathrm{~W} \cdot \mathrm{m} \cdot \mathrm{K}$ at $8.6 \times 10^{\circ 4}$ neutrons, $\mathrm{m}^{2}$ was obtained on a slug-injected fuel rod with a tolal particle londing near 58 vol \% $\%$. Part of this, however, was graphite shim so that the simulated fucl particles conumed on! $16.5 \mathrm{vol} \%$. Therefore, this datum can be compared to the extruded specimen with 35- -61 ); particles. This comparison at $8.6 \times 10^{23}$ neutrons: $m^{2}$ showed that the ratio of $\lambda$ from the extruded naterial to $\lambda$ from the slug-injection material was 2.6 .

- Ihis ator permilled use of the two data sets generaled in the I.TL, which has an upper temperature near $400 \mathrm{~K}$. 


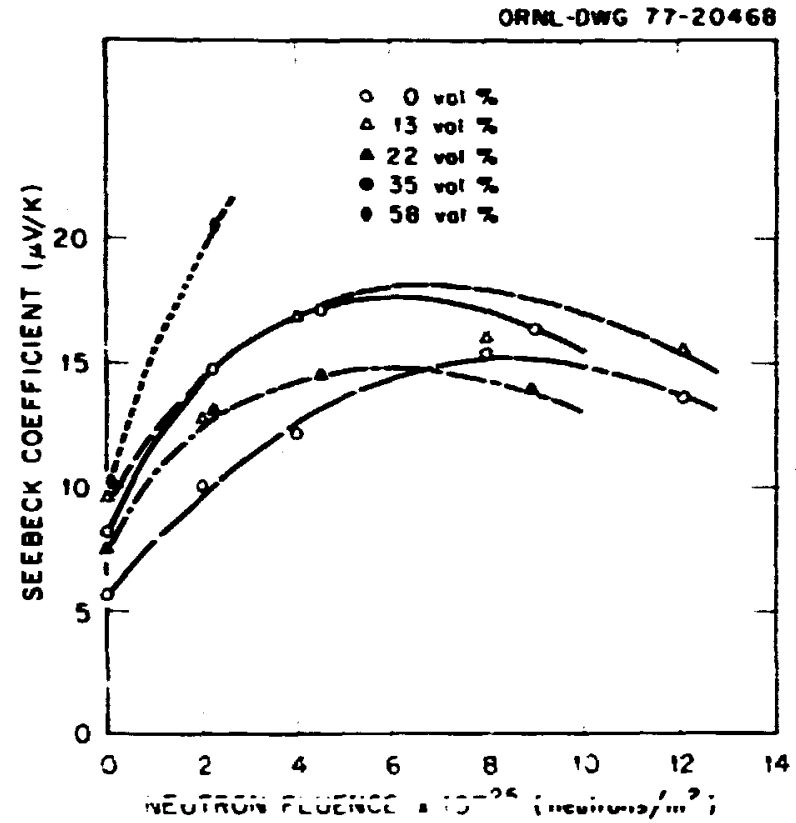

Fig 15. Absolute $S$ of simulated fuel rods near $390 \mathrm{~K}$ vs reutron fluence showung the maximum that occurs for each particle londing-

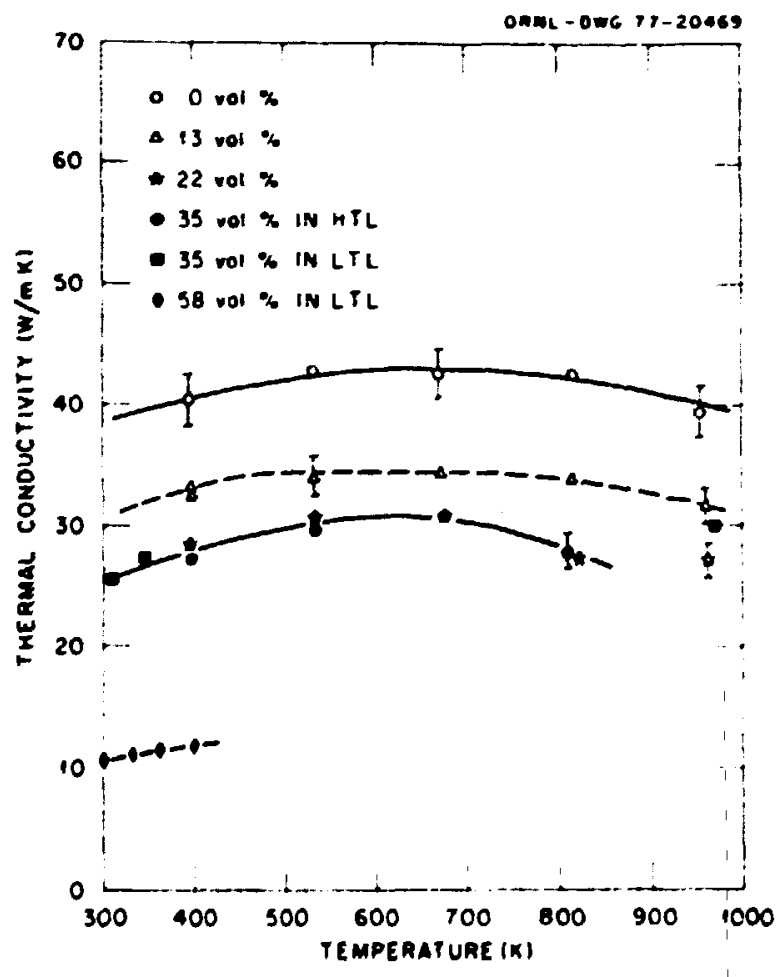

Fig. 16. Thermal conductivity of exinded and slugeinjected fuel rods after one cycle in HFIR $\left(\sim 2 \times 10^{2 \prime}\right.$ neutrons $\left./ \mathrm{m}^{2}\right)$ showing the low $\lambda$ of the specimen containing 58 -vol $\%$ particles and the $\lambda$ agreement of the 23-and 35.vol \% specimens. 


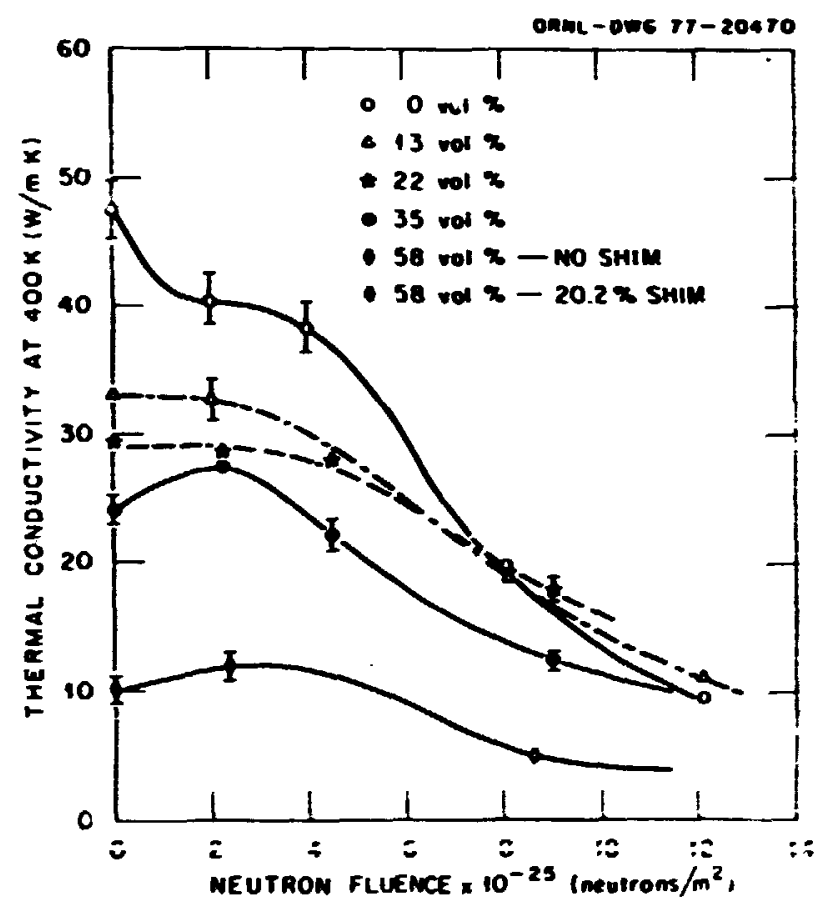

Fig. 17. The $A$ at $400 \mathrm{~K}$ vs fuence showing the initial increases in $A$ of the extruded specimen with 35-vol cr particle and the slug-injected specimen. The high nuence decrease in $A$ of all specimens is also show $n$.

\section{DISCUSSION OF RESULTS}

The materials studied in this work were complex-multiphase solids. Even the simplest extruded specimen with 0-vol \% particles consisted of anisotropic graphite flake, carbonaceous pitch between the lakes, and pires of all shapes. Specimens containing simulated fuel particles were the most complex because each particle consisted of three distinct phases. Thus, most specimens consisted of six distinct phases and the effects of these on the $\lambda, \rho, S$, and CTE were difficult to access because neutron nuence, irradiation temperature, and measurement temperature usually have different effects on each phase. Generally, a total property change is the sum of several mechanisms acting on different phases; these mechanisms sometimes compete and sometimes augment each other. Therefore, in this discussion we present some possible explanations and indicate the problem areas with the analysis.

\section{Coefficient of Therimal Expansion}

The CTE results at 298 and $973 \mathrm{~K}$ indicate that complex stress states occur in the extruded specimens and are quite different for the pure matrix sample and for those containing coated particles. It shor'd be remembered that these samples were heal treated at $2100 \mathrm{~K}$ during fabrication. were irradiated at a nominal $1220 \mathrm{~K}$, and were measured to only $973 \mathrm{~K}$. One may reasonably assume that the specimens were essentially stress free at $2100 \mathrm{~K}$, but on cooling to room temperature, interaction between the matrix (unirradiated CTE of $\sim 2 \times 10^{-n} \cdot K^{\prime}$ ) and the particles (unirradiated CTE of $\sim 3.75 \times 10^{-6} \cdot \mathrm{K}$ ) would cause significant stress. The observed linear relation of CTF to particle loading for the unirradiated samples at 298 and at $973 \mathrm{~K}$ is a strong indication that microcracks are 
not significant factors. This implies that. at least for the extruded specimens, residual stress must increace with particle loading but does not exceed the strength of the body.

After neutron irradiation, the thermal expansion characteristics are changed markedly as shown in Fig. 12 and are still quite different for the pure matrix and for the samples that contain particles. At $298 \mathrm{~K}$, the 0-yol $\%$ particle sample had the lowest CTE after one HFIR cycle. and then the CTE increased with fluence, approaching the unirradiated :aluc. The particle-containing samples experienced a similar decrease in CTE at $298 \mathrm{~K}$ after the first HFIR cycle, but the CTE continued to decrease with increasing flue $c e$. This is most pronounced for the $22-v 01 \%$ sample. but much less so for the 13 vol $\%$. It is :nfortunate that four- and six-cycle data could not be obtained for the 35\% samples, but the one-and two-cycle troults are essentially the same as for the $22 \%$ samples. At $973 \mathrm{~K}$. the 0-vol Gamples had CTEs almost independent of nuence and equal to the unirradiated sample. The loaded samples showed the same trends at the high temperature as at $298 \mathrm{~K}$ with a decrease in CTE with fluence, but the change is somewhat less for higher fluences.

T'iese results suggest that at least two different mechanisms are affecting the expansion behavior of these samples after neutron irradiation. First, the measured volume decrease on irradiz'ion (Fig. (I) and the corresponding decrease in CTE at $298 \mathrm{~K}$ coupled with the very small change in CTE at $973 \mathrm{~K}$ is indicative of extensive microcracking caused by unequal irradiation-induced shrinkages of the graphite filler flakes and the carbonaceous binder in thenct-Inading samnles Further nout mn irrodiatien res.ules in a volume increase which tends to close these microciacks in the matrix material so they have a decreasing effect on CTE. Second, the similar volume changes in the particle-containing samples, but the completely opposite CTE changes with increasing fluence. suggest a strong particle-matrix interaction. A possible mechanism would be a densification of the outer layer of the microsphere and graphitization-densification of the adjacent matrix material. This would result in a net tensile stress throughout the matrix and a corresponding decrease in CTE at both the low and high temperatures. This second mechanism would tend to be tempered by microcracks as suggested by the general coalescence of the rzsults at $973 \mathrm{~K}$. but the net tensile stresses still dominate.

\section{Transport Properties}

The thermal conducivity $(\lambda)$ behavior of the simulated fuel rods is rather complex because there are many components including carbon core. pyrolytic carbon coatings. filler flake, and carbonaceous material between filler Makes and particles. Within each solid component there are three possible conduction mechanisms, so the total $\lambda$ is given b;

$$
\begin{aligned}
& \lambda_{r}=\lambda_{r}+\lambda_{r}+\lambda_{r} \\
& \lambda_{r}=\text { omponent due to quantized lattice vibrations. } \\
& \lambda_{r}=\text { electronic component. } \\
& \lambda_{r}=\text { radiation component. }
\end{aligned}
$$

In all solids within these fuel elements, $\lambda$, and $\lambda$, are negligible, so heat conduction is due to quantized lattice vibrations or phonons. The value of $\lambda$, could definitely differ in each component. In addiiion to the conduction through various solid components. some heat possibly could be conducted across pores by radiation or gasenus conduction. Although both of these are riegligibly small, pores still have all effect on $\lambda$. Spheroidal pores have relatively small effects on $\lambda$ compared to the effect of flat 
or open pores aligned so that the normal to the pore plane is parallel to the heat-flow direction. The behavior of $\rho$ often provides an indication of how $\lambda$ will behave.

The plateaus in the $\rho$ curves (Fig. I3) between $3 \times 10^{\circ \prime}$ and $5 \times 10^{\circ}$ neutrois in and the increase in $\lambda$ of the specimens containing 22-, 35-, and 58-vol $\%$ particles are two of the most interesting features of the data. The relationship of these two properties presents a possible reason for the $\lambda$ behavior. Figure 18 shows a solid curve ${ }^{\prime i}$ for the thernal conductivity versus the electrical conductivity, $\sigma=\rho$. which passes within $\pm 10 \%$ of most data on dense, isotropic, and unirradiated graphites. As graphites of this type are irradiated with neutron:, the values move away from the curve as noted by results on AXM-5Q and H-337 graphite. 'This reduction in $\lambda$ is caused by carbon atoms being disordered within or removed from the basal planes of the graphite particles within the isotropic solid. ?his disordering by neutrons actually moves the graphite material back toward a carbonaceous state similar to its condition prior to graphitization by heating to temperatures of 2800 to $3000 \mathrm{~K}$.

However, several components of the sir.slated fuel rods in this investigation were poorly graphitized because the highest temperature employed during fabrication was only $2100 \mathrm{~K}$. This poor graphitization of at least one important component within the fuel rod causes the $\lambda: \sigma$ values to fali significantly below the curve for graphite. The $\lambda: \sigma$ relation is nearly linear with data scatter within $\pm 7 \%$. After one irradiation cycle $\left(\sim 2 \times 10^{-4}\right.$ neutrons $\left./ \mathrm{m}^{2}\right)$, the results from the simulated luel rods move closer to the curve for graphite. With additional irradiation the $\lambda: \sigma$ values begin to decrease, but this is not shown in the figure. Thi behavior indicates that neutron irradiation at the high irradiation temperatures ${ }^{*}(\sim 1223 \mathrm{~K})$ caused increased lattice order within all specimens including those fabricated by slug injection. Previous investigators ${ }^{4}$ have ascribed this increase to ordering of the carbonaceous material immediately adjacent to the graphite filler lakes duc to high-temperature neutron irradiation.

The fuel rods are complex composite sysiems with regard to energy transport. and it is difficult to state categorically the functions of each component in the total property behavior. There sre. howeter. several possibilities including the following.

1. The thermal conductivity, $\lambda_{m}$, of the matrix material surrounding the fucl particles is the same (with the exception of a slight shift for minor density variation) as the thermal conductivity of the extruded specimen with no particles present. In this case the effective particle thermal cond uctivity, $\lambda_{p}$, would be free to move as needed $t$ ) give the net $\lambda$.

2. The $\lambda_{p}$ remains constant with fluence and $\lambda_{m}$ would have a different behavior than does $\lambda$ of the 0-vol $\%$ element.

3. A combination of the above two.

The first possibility is examined in Appendix B based on composite studies by others. "...' The results, which are shown in Fig. 19, would indicate that $\lambda_{p}$ increases during the first cycle. decreases during the second, and then increases rapidly up to the maximum flucnce of $12.1 \times 10^{: 4}$ neutrons $\mathrm{m}^{2}$. The $\lambda_{p}$ of $50 \mathrm{~K} / \mathrm{m} \cdot \mathrm{K}$ after $12.1 \times 10^{24}$ neutrons, $\mathrm{m}^{2}$ appears unreasonably large. but values over $400 \mathrm{~W} / \mathrm{m} \cdot \mathrm{K}$ have been measured along the basal planes of pyrolytic carbon with a density of $2.1 \mathrm{Mg} \mathrm{m}^{\text {i }}$

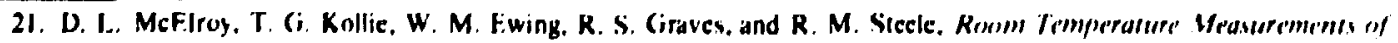

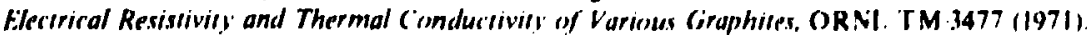

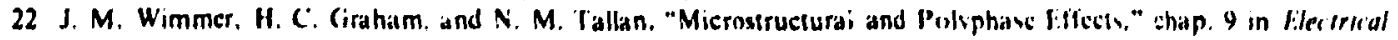
Condur'vivily in Ceranurs and (ilass, Farl B. N. M. Tallan. F.d. Marcel Dekker. Inc N.Y.. 1974.

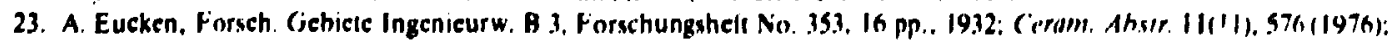
Ceram. Ahstr. 12(6). 23! (19.3.3). 


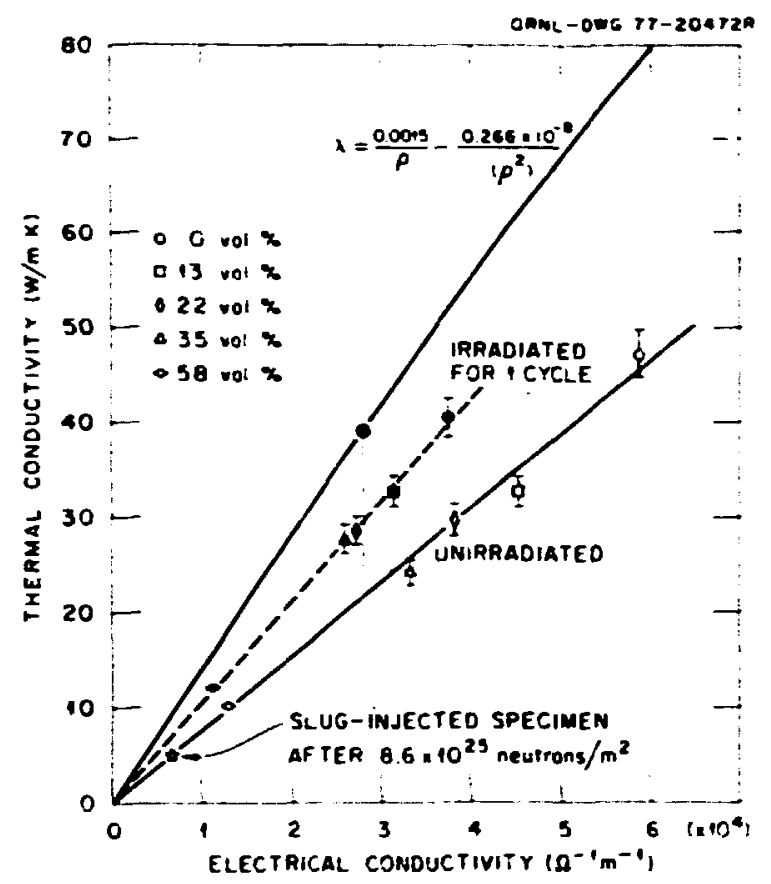

Fig. 18. The $A$ is $a(\rho)$ of the simulated fuel rods prior to irradiation and after une cycle in HFIR. A cumpariwn line fior

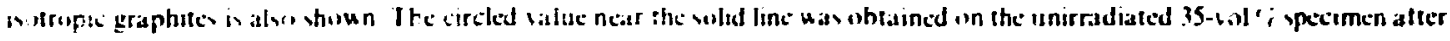
hesting (o 2 Y(N) $K$ tor I $A$ h.

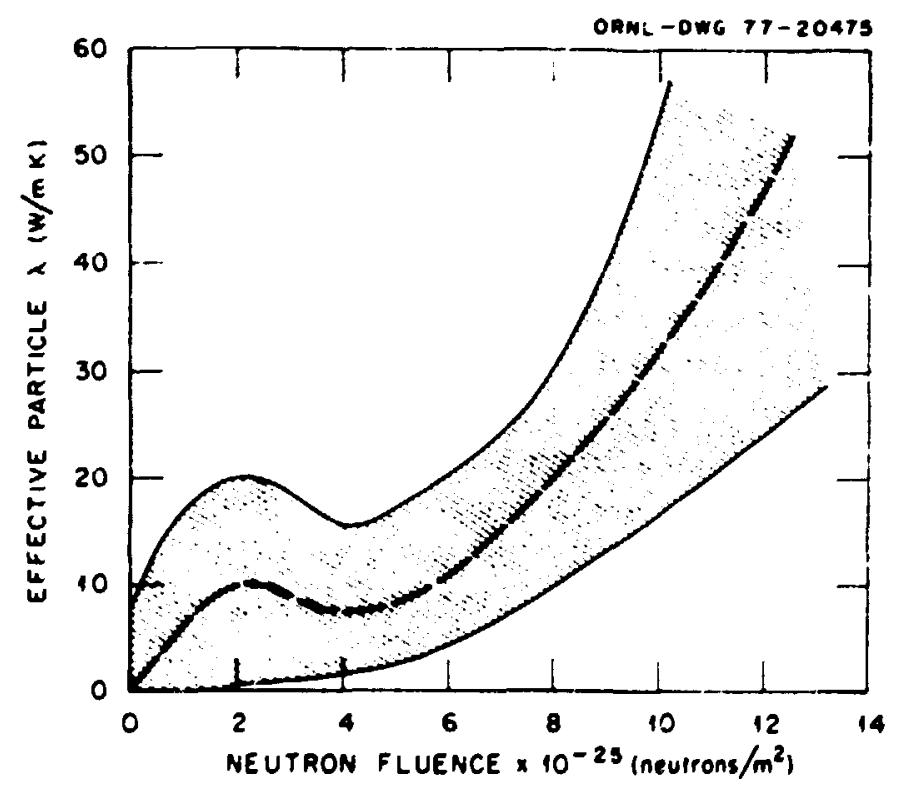

Fig. 19. Iffective particle thermal conductivity. $\lambda_{p}$ showing the increase with increasing neutron fuence calculated on this midel. 
(ref. 24). (as compared '"' the $2 \mathrm{Mg} \mathrm{m}^{\prime}$ in the present case). The basal (high thermal conductivity direction) planes art aligned is such a manner that they have the maximum effect in conducting heat around the particle and her'e a maximum effect on $\wedge$ of the simulated fuel rods. Pyrolytic carbons that were iriadiated in the same capsules emplojed for this study" showed that the anisotropy: as determined by BAF nieasurements. increased with neutron fluence and. further, that the anisotropy increase was much greater when the psyolytic carbon was constrained during neution irradiation. Thermal expansion differences within the simulated fuel rods of this study would have caused strain on the outer coatings of the particles. Therefore, some increase in $\lambda_{r}$, would not be surprising since the combination of neutron f.ux and mechanical stress on the outer pyrolytic carbon could have caused sufficient strain to improve the basal plane alignment around the particle surface. Quantitative calculations on this would be difficult - if not impossible - because the ordering is sensitive to many parameters including coating deposition rate and mechanical strain.

The second possibility for explaining the $\lambda$ and $\rho$ results involves the assumption thai $\lambda_{m}$ between the particles of extruded elements does not behave as does the element that contains no particles. Other investigators have shown that neutron flux on a carbonaceous material at high temperature causes a partial orjering around the small graphite filler flakes. This partial ordering can cause a net increase in $\lambda$, although $\lambda$ of the filler flakes begins to decrease with the inception of neutron flux. This effect is seen in Fig. 16, which shows a distinct inflection of $\lambda$ versus fluence for the specimen with 0-vol \% particle loading. This partial ordering around filler flakes is increased when the carbonaceous material is strained by the presence of particles. Thus, the sperimens with the most particles would be expected to show the greatest effect as was observed in this case; the 35 -and 58 -vol $\%$, specimens have the greatest percentage of $\lambda$ increase.

The most likely explanation is that the transport properties results were controlled by a combination of the above two factors. Tha: is, the snitial increases in $\lambda$ of the 35-vol $\%$ extruded and 58-vol $\%$ slug-injected simulated fuel rods and the curvatures of the $\lambda$ versus fluence curves of the 13- and 22-vol \% specinens are due to an unknown combination of ordering within the outer partick coating and within carbonaceous material adjacent to filler fakes. The latter effect caused the inflection in the $\lambda$ versus fluence curve for the extruded specimen with no particles present.

If this general interpretation is correct, heat treatment of some simulated fuei elemelıts to temperatures normally employed for graphitization should change the properties in a manner analogous to the first irradiation cycle. This was tested by heat treating the unirradiated extruded specimen with 35-vol cir particles to $2900 \mathrm{~K}$ for $1.8 \mathrm{ks}$. This treatment increased the $n$ from $30 \mu \Omega \cdot \mathrm{m}$ to $35.6 \mu \Omega \cdot \mathrm{m}$, which is similar to the initial irradiation cycle increase to $38.7 \mu \Omega \cdot \mathrm{m}$. The $\lambda$ at $400 \mathrm{~K}$ increased from $24.4 \mathrm{~W}, \mathrm{~m} \cdot \mathrm{K}$ to $39.0 \mathrm{~W} / \mathrm{m} \cdot \mathrm{K}$, which is also similar to the $\lambda$ increase during the first cycle of neutron irradiation. This result is shown in Fig. 18. Graphitization at $2900 \mathrm{~K}$ also increased the absolute Seebeck coefficient in the same way as the initial neutron irradiation. This behavior of these three properties tends to substantiate the interpretation of parial graphitization occurring in some important conduction phase (probably the carbonaceous material within the matrix) during the first irradiation cycle.

24. Y. S. Toulnukian, Fd. "Filements," p. 49 in Thermophysical Properties of High Temperoture Solid Malerwals, vol 1. Purduc Research Foundation. 1967.

25. J. E. Kaac, R. F. Bullock. C. B. Scolt. and D. P. Harmon. The Mecnonical Behovisur of BISO) (ionled Fivel Parlirle, I. uring Irradiation. Porls I and II, (;A-Al \$092 (July 1976) 
Wagner:- his incesigated the efiects of tinal heat-treatment temperatures on graphite flour bonded with potstisturs' alcohol and graphite llour bonded with pitch. The $\lambda$ values that he obtained are within 12f; of the pr :xent value cor unirradiated material with 0-vol $;$ ioading after corrections are made to a common densits. This agreement is excellent when one considers the crrors involved with experimental measurements ani vagaries of fabrication. Wagner's results shou that the thermal conductitity of the 0-i ol \% specimen probahly could be increased about 60 ; by increasing the final fucl element heat-treatment temperature from $2 I(M)$ to $2800 \mathrm{~K}$. At $410 \mathrm{~K}$ the $\lambda$ increase in the above sp:cimen was 59.8\%; Although this increased $\lambda$ irom the higher heat treatment possibly would be short lived under neutron irradiation. it would significantly reduce the gradient across the fuel particles in the initial stages of reactor operation.

The explanation of the ( TE results was bascit on microcracks apparing in the matrix material during irradiation. These microcracks. if present. would negate part of the possible $\lambda$ increase around the filler tlakes. As mentioned carlier. hou ever, the various propertics are rebatcd to many variables in different uass so that the explanations of hoth (TE and the tratsport propertics are yualitatively correct.

As an addendum to this work. the of of production fucl elements containing Th( ): particles was measured versus shim loading. These reiults. which are deveribed in Appendix $C$. show that $p$ decreases uith increasing shim conten?. but cten a high shim loading does not eliminate the effect of the lou-density slug-injection matrices in increasing $\rho$.

\section{CONCLUSIONS}

1. Ihe $\lambda$ of simulated - - veruded fuel rods $u$ as a factor of 2 to + great:er than the $\lambda$ of siag-injected fuel rod depending on the comparison temperature and neutron tluence. The $\lambda$ of the unloaded extruded specimens (1) : ol ' ;) decreasev with increasing neutron fluence. whercas $\lambda$ of the specimens with high loading tend to increase initialis and then decrease at high neutron fluence.

2. The of of ech loading increases with neut ron fluence. However. the pof the extruded specimens tends to platcau ove: a $u$ ide fluence range followed hy a rapid increase at high fluence. whereas the $\rho$ of slug-injected specimens appears to increase corrinually $w$ ith tluence.

3. Atcer a neutron tluence of $8.6 \% 10$ neutrons $\mathrm{m}$. a slug-injected simulated fuel rod has a $\lambda$ of $5 \mathrm{~W} \mathrm{~m} \cdot \mathrm{K}$. Which in ahout 3$)^{\prime} ;$ belou the HT(ik design value of $6.9 \mathrm{~W} \mathrm{~m} \cdot \mathrm{K}$

4 Inaly is of the, and $\lambda$ datla suggests that a partial ordering ociur in the luel rods during netronn irradiation as $1223 \mathrm{~K}$ Ihis concept is upported tis the behaviot of a 35 -vol', specimen when byat treased (:) 291K) K. Therelore. some ordering ma! be ociurring around the graphite filler flakes in the carbonaceous natrix. and this ordering tend, tw increase the fuct clernent $\lambda$. This increase is being countered by decreases in $\lambda$ of the filler flakes as ucll as powible microcracking. Assumption that the matrix material hetucen the particles of extruded fuel rods has the same $\lambda$ as the unloaded cxtruded fuel rod leads to a calculated eflectice particle $\lambda$ that increases to unreasonably high values.

5. Prior to iradiation the (If of each specimen increases smowthly with temperature. and CTE at any temperature increases smooshly with increasis.g particle loading.

6. Atter irradiation the (TEs of these materials are no longer strongly dependent on volume percent particle loading or neutron fluence. and temperature has a reduced effect.

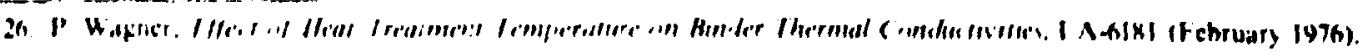


7. The (TE and volume change data suggest that extensive microcracking may be orcurring in the carbonace ous hinder hetween filler flakes and that the particles and matrices are bonded strongly. which causes tensile stress throughout the matrices.

\section{RECOMMENDATIONS}

1. Irradiation temperatures other than the one used in this experiment could make $A$ differ from these results. Thus caution should be exercised in application of the data.

2. The macroscopic $\lambda$ of the slug-injected fuel rods should not be used for calculation of temperature gradients across fuel particles because the matrix of slug-injected rods can be so porous that many particles are almost surrounded by gas. Hence, across any particle the gradient could be greater or less than calculated.

3. Properties of slug-injected material $u$ ith inen particles should be determined versus shim loading and type, irradiation temperature, and neutron fuence. The $A$ of unirradiated slug-injected tucl rods containing actual fucl particles should be determined versus shim concentration.

4. Detailed ceramography of all specimens in this study should be done to verify the conclusions drawn with regard io the behavior of carbonaceous material between filler fike during neutron irradiation.

5. Routine $p$ measurements might be useful to determine the homogeneity of actual fuel rods. Although these neasurements would have to be made on unfired fuel elements, large defects such as racks should be dcicctable.

\section{ACKNOWLEDGMENTS}

The authors are grateful to D. E. Rosson, R. I. Hamner, and J M Robbins for sample fabrication and also to the lattic for answering numerous questions. Wealso thank $P$. Angelini for obtaining some production specimens ard R. I. Beatty and D. L. McElroy for constructive comments on the test. We also toke this opportunity to express our gratitude to Sharon Buhl for her patience in the draft preparation. The report was edited and prepared for reproduction by the Technical Publications Department. 


\section{Appendix A \\ EXPERIMENTAL DATA}

Measured values of $\rho$. $S$, and $\lambda$ for the simulated fuel rods involved in this study are given in Tables A-I through A-6. In addition to the tabulat.d $p$ results for each specimen. $\rho$ values obtained near $300 \mathrm{~K}$ on a knife edge are given in Tables $I$ and 6 of the main text.

An archive slug-injected specimen with 36.5-vol $\tau_{i}$ simulated fuel particles and 20.2-vol \%? shim produced a $\lambda$ of $4.9 \mathrm{~W} \cdot \mathrm{m} \cdot \mathrm{K}$ at $294.2 \mathrm{~K}$ and $5.2 \mathrm{~W} \mathrm{~m} \cdot \mathrm{K}$ at $350.6 \mathrm{~K}$ after $8.6 \times 10^{\circ 4}$ ncutrons: $\mathrm{m}^{2}$ IE $>28.8$ [:;.

Table A-1. Measured velues of p.S. and $\lambda$ of exiruded specimens with 0rol $x$ perticte londiag

\begin{tabular}{|c|c|c|c|}
\hline $\begin{array}{c}\text { Temperature } \\
\text { IK }\end{array}$ & $\stackrel{\lambda}{\lambda(w / m-k)}$ & $\begin{array}{c}S \\
(\mu V / K)\end{array}$ & $\stackrel{p}{(\mu \Omega 2-m)}$ \\
\hline \multicolumn{4}{|c|}{ Cnirradiated } \\
\hline 393.9 & +7.5 & 5.8 & \\
\hline 538.1 & 45.1 & 5.3 & 14.8 \\
\hline 673.0 & +3.7 & 4.6 & 14.1 \\
\hline 815.7 & 43.0 & 4.3 & 13.6 \\
\hline 952.8 & 38.6 & 4.8 & 13.2 \\
\hline 952.8 & 35.6 & 4.8 & \\
\hline 533.9 & 48.0 & 5.3 & \\
\hline \multicolumn{4}{|c|}{$2.02 \times 10^{25}$ neutrons: $m^{2}$ I cycle in IIFIR } \\
\hline 393.0 & & & 24.2 \\
\hline 397.2 & 40.5 & 10.1 & \\
\hline 532.5 & 42.8 & 9.8 & 21.3 \\
\hline 6723 & 426 & 8.6 & 19.0 \\
\hline 806.4 & 43.0 & 7.5 & 17.5 \\
\hline 953.9 & 39.4 & 6.7 & 16.1 \\
\hline \multicolumn{4}{|c|}{$4.03 \times 10^{25}$ neutrons: $\mathrm{m}^{2} 2$ cyckes in HFIR } \\
\hline 992.8 & 38.4 & 12.2 & 28.8 \\
\hline 534.8 & 39.4 & 12.2 & 26.1 \\
\hline 675.6 & 38.0 & 11.1 & 22.9 \\
\hline$x 13.5$ & 36.9 & 9.7 & 20.4 \\
\hline$y \$ 2.6$ & & 8.5 & 18.4 \\
\hline 392 is & 38.8 & 11.1 & 26.1 \\
\hline \multicolumn{4}{|c|}{$8.05 \times 10^{25}$ neutrons $/ \mathrm{m}^{2}+$ cycles in HFIR } \\
\hline 394.9 & 20.0 & 15.4 & 36.5 \\
\hline 531.3 & 21.7 & 17.6 & 32.8 \\
\hline 671.4 & 21.7 & 18.4 & 29.7 \\
\hline 809.3 & 21.8 & 17.5 & 27.1 \\
\hline 95s.1 & & 16.2 & 24.9 \\
\hline 531.2 & 21.9 & 15.6 & 33.2 \\
\hline \multicolumn{4}{|c|}{$12.1 \times 10^{25}$ neutrom $/ \mathrm{m}^{2} 6 \mathrm{cycles}$ in HFIR } \\
\hline 393.8 & 9.3 & 13.6 & 63.4 \\
\hline 532.9 & In.s & 16.6 & 58.4 \\
\hline 674.4 & 11.1 & 18.4 & 53.7 \\
\hline 809.9 & 11.4 & 18.8 & 49.8 \\
\hline 955.2 & 11.4 & 18.8 & 46.0 \\
\hline 533.6 & 10.5 & 15.9 & 59.0 \\
\hline
\end{tabular}


Table A.2. Messured values of $\rho .5$, and $\lambda$ of extruded material with 13-rol $\mathrm{x}$ perticle loadiag

\begin{tabular}{|c|c|c|c|}
\hline $\begin{array}{l}\text { Temperature } \\
\quad(\mathbf{K})\end{array}$ & $\stackrel{\lambda}{(w / m \cdot k)}$ & $\begin{array}{c}S \\
(V / K)\end{array}$ & $\underset{(\mu \Omega \cdot m)}{\rho}$ \\
\hline \multicolumn{4}{|c|}{ Liairradiated } \\
\hline 393.4 & 328 & 9.7 & a \\
\hline 532.0 & 35.0 & 7.6 & a \\
\hline 667.9 & 35.1 & 6.0 & $a$ \\
\hline 805.6 & 34.2 & I.I & $a$ \\
\hline 950.4 & 31.5 & 3.6 & $a$ \\
\hline 533.2 & 34.8 & 5.8 & $a$ \\
\hline \multicolumn{4}{|c|}{$2.02 \times 10^{25}$ aeutrons $/ m^{2} 1$ cyck in HFIR } \\
\hline 397.8 & 325 & 12.8 & \\
\hline 396.6 & 33.3 & 13.4 & 23.2 \\
\hline 532.3 & 34.1 & 13.6 & 25.8 \\
\hline 672.9 & 34.3 & 12.0 & 23.2 \\
\hline 813.5 & 34.0 & 10.5 & 21.2 \\
\hline 948.0 & 31.7 & 9.7 & 19.7 \\
\hline \multicolumn{4}{|c|}{$4.03 \times 10^{25}$ neutrons/ $m^{2} 2$ cycles in IIFRR } \\
\hline 392.3 & 29.5 & 16.9 & 31.7 \\
\hline 531.3 & 30.2 & 17.5 & 28.1 \\
\hline 676.7 & 30.0 & 16.6 & 25.0 \\
\hline 813.0 & 29.2 & 14.9 & 22.8 \\
\hline 954.1 & 29.7 & 12.9 & 20.7 \\
\hline 393.1 & 28.8 & 15.8 & 31.7 \\
\hline \multicolumn{4}{|c|}{$8.05 \times 10^{25}$ meutrons $/ \mathrm{m}^{2} 4$ cycles in HFIR } \\
\hline 393.7 & 18.7 & 15.9 & 40.62 \\
\hline 532.5 & 20.3 & 18.3 & 36.56 \\
\hline 673.2 & 20.9 & 19.1 & $33.0 \times$ \\
\hline 814.0 & 20.8 & 18.2 & 30.11 \\
\hline 956.2 & 20.7 & 16.7 & 27.47 \\
\hline 392.9 & 19.1 & 14.8 & 40.41 \\
\hline \multicolumn{4}{|c|}{$12.09 \times 10^{25}$ newtrons $/ \mathrm{m}^{2} 6 \mathrm{cycles}$ in HFIR } \\
\hline 394.2 & 11.4 & 15.5 & 62.0 \\
\hline 534.3 & 12.4 & 17.8 & 55.7 \\
\hline 673.7 & 12.6 & 18.4 & So, 4 \\
\hline 813.4 & 12.5 & 17.6 & $\$ 5.9$ \\
\hline 955.2 & & & $\$ 1.9$ \\
\hline 538.3 & 12.2 & 16.4 & 55.4 \\
\hline
\end{tabular}

${ }^{a}$ Losl current lead which prevented 0 measurements. 


\begin{tabular}{|c|c|c|c|}
\hline $\begin{array}{l}\text { Temperature } \\
\text { (K) }\end{array}$ & $\stackrel{\lambda}{(w / m-k)}$ & $\underset{(\mu v)}{S}$ & $(R \Omega-m)$ \\
\hline \multicolumn{4}{|c|}{ Cinisediaked } \\
\hline $392 . ?$ & $=2.5$ & 7.5 & 24.9 \\
\hline 530.0 & 30.3 & 8.1 & 23.2 \\
\hline 671.9 & 306 & 2.2 & 22.0 \\
\hline 807.1 & 29.9 & 24 & 21.2 \\
\hline $681.6^{\circ}$ & 30.3 & 6.9 & 22.0 \\
\hline 956.4 & 30.2 & 9.3 & 20.4 \\
\hline 397.1 & 28.6 & 13.2 & 33.5 \\
\hline$\$ 35.0$ & 30.7 & 129 & 29.4 \\
\hline 677.1 & 31.0 & 11.5 & 20.2 \\
\hline 814.5 & 27.9 & 9.9 & 23.9 \\
\hline 960.2 & 27.2 & 29 & 22.0 \\
\hline \multicolumn{4}{|c|}{ 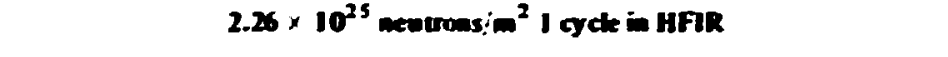 } \\
\hline 393.2 & 280 & 14.5 & 36.1 \\
\hline 533.8 & 289 & 14.7 & $31 . ?$ \\
\hline 6729 & 285 & 13.7 & 28.2 \\
\hline 8128 & 27.8 & 120 & 25.4 \\
\hline 954.3 & 27.0 & 10.7 & 23.1 \\
\hline 534.2 & 289 & 14.0 & 31.5 \\
\hline \multicolumn{4}{|c|}{$4.5 \times 10^{25}$ mectronsim 2 cyches in HFIR } \\
\hline 393.4 & 180 & 13.9 & $\$ 7.2$ \\
\hline 533.6 & 19.2 & 15.2 & 42.0 \\
\hline 673.4 & 19.3 & 15.0 & 37.6 \\
\hline 813.8 & $18 ?$ & 13.9 & 33.9 \\
\hline 9530 & 18.4 & 128 & 30.9 \\
\hline 533.9 & 19.1 & 14.3 & 41.9 \\
\hline \multicolumn{4}{|c|}{6 cyctes in HFIR } \\
\hline \multicolumn{4}{|c|}{ Broken } \\
\hline
\end{tabular}




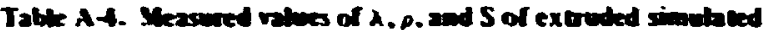
fecl rods contining 35-vol $g$ pertick bouling

\begin{tabular}{|c|c|c|c|}
\hline $\begin{array}{c}\text { Temperature } \\
\text { (N) }\end{array}$ & $(x / m-k)$ & $\stackrel{S}{(\mu V ! K)}$ & $(\mu)$ \\
\hline \multicolumn{4}{|c|}{ Liningediatad } \\
\hline 395.9 & 24.4 & 8.3 & 28.4 \\
\hline 536.9 & 24.6 & 9.5 & 26.6 \\
\hline 571.8 & 24.2 & 10.3 & 25.3 \\
\hline 823.9 & 22.0 & 11.2 & 24.3 \\
\hline 953.6 & & & 23.9 \\
\hline \multicolumn{4}{|c|}{ I cycle in HFIR } \\
\hline 394.6 & $2 ? .5$ & 14.9 & 35.3 \\
\hline 534.5 & 29.9 & 15.0 & 31.2 \\
\hline 672.7 & 31.0 & 13.9 & 28.0 \\
\hline 811.3 & 27.9 & 12.1 & 25.4 \\
\hline 952.6 & $31) .0$ & 11.3 & 22.9 \\
\hline \multicolumn{4}{|c|}{ Chect of I gele specinien in low-experature knojitudiand } \\
\hline 3199.7 & 26. I & & \\
\hline 308.7 & 25.6 in & & \\
\hline 348.1 & 27.7 & & \\
\hline \multicolumn{4}{|c|}{ t.5 $; 10^{25}$ neetronsim 2 cycles in IIFIK } \\
\hline 399 & 22.4 & 17.2 & 36.6 \\
\hline 534 & 25.0 & 18.0 & 32.5 \\
\hline 673 & 27.3 & 17.1 & 29.1 \\
\hline 812 & 27.9 & 15.5 & 26.5 \\
\hline 955 & 29.9 & 14.7 & 24.0 \\
\hline \multicolumn{4}{|c|}{$9.0 \times 10^{25}$ neutroms $/ \mathrm{m}^{2} 4$ cycles in HFIR } \\
\hline$+2=$ & 12.9 & 16.3 & 46.2 \\
\hline 576 & 13.4 & 17.9 & 40.9 \\
\hline 723 & 14.7 & 17.9 & 36.6 \\
\hline 874 & 13.4 & 16.6 & 33.1 \\
\hline \multicolumn{4}{|c|}{6 cyctes in MFIR } \\
\hline \multicolumn{4}{|c|}{ Broklen } \\
\hline
\end{tabular}

Table A.5. Measuned tansport propentios of an unistadiated 35-rol \% excruded specimen afer heat treatment is $2900 \mathrm{~K}$ for $1.8 \mathrm{ks}$

\begin{tabular}{cccc}
$\begin{array}{c}\text { Temperalure } \\
(K)\end{array}$ & $\begin{array}{l}\lambda \\
(W / \mathrm{m} \cdot \mathrm{K})\end{array}$ & $\begin{array}{c}S \\
(\mu \mathrm{V} / \mathrm{K})\end{array}$ & $\begin{array}{c}\rho \\
(\mu \Omega \cdot \mathrm{m})\end{array}$ \\
\hline 295.0 & & & 35.6 \\
394.1 & 39.4 & 9.71 & \\
473.6 & 38.0 & 8.78 & 7.29 \\
574.0 & 35.8 & & \\
\hline
\end{tabular}




\begin{tabular}{|c|c|c|c|}
\hline $\begin{array}{c}\text { Temperalure } \\
\text { (K) }\end{array}$ & $(n: m \cdot k)$ & $\begin{array}{c}5 \\
(\mu \mathrm{V} / \mathrm{K})\end{array}$ & $\stackrel{p}{(\mu \Omega \cdot m)}$ \\
\hline \multicolumn{4}{|c|}{ Creirradianed } \\
\hline 393.9 & 9.9 & 10.1 & 74.0 \\
\hline 532.5 & 10.3 & 12.8 & 68.9 \\
\hline 675.8 & 12.2 & 14.8 & 63.5 \\
\hline 813.7 & 9.8 & 16.4 & 60.5 \\
\hline 963.6 & 10.5 & 18.0 & 55.9 \\
\hline 394.7 & 10.4 & 9.9 & 71.6 \\
\hline \multicolumn{4}{|c|}{1 cycke } \\
\hline 298.4 & 10.7 & 19.3 & \\
\hline 332.7 & 11.2 & 20.4 & \\
\hline 363.8 & 11.5 & 20.5 & \\
\hline 400.7 & 11.8 & 20.8 & \\
\hline
\end{tabular}

\section{Appendix B}

\section{CALCULATION OF AN EFFECTIVE PARTICLE $\lambda$ ASSUMING THAT $\lambda_{\text {mans }}$ BEHAVES AS DOES $\lambda$ OF THE UNLOADED SPECIMEN}

Many attempts have been made to mathematically relate the component $\lambda$ values to $\lambda$ of the composite, and some of these attempts are discussed elsewhere." The most frequently employed equation: is

$$
\lambda \lambda_{m}=\frac{1-2 p\left(\lambda_{m}-\lambda_{p}\right)\left(2 \lambda_{m}+\lambda_{p}\right)}{1-p\left(\lambda_{m}-\lambda_{p}\right)\left(2 \lambda_{m}+\lambda_{p}\right)} .
$$

where

$$
\begin{aligned}
& \lambda=\text { thermal conductivity of com:posite, } \\
& \lambda_{m}=\text { thermal conductivity of the continuous phase, } \\
& \lambda_{p}=\text { thermal cond uctivity of the discontinuous phase. } \\
& p=\text { volume fraction of discontinuous phase. }
\end{aligned}
$$

This equation was derived for composites with discontinuous-spheroidal particles separated sufficiently that the thermal field becomes uniform between adjacent particles. The latter restricts use of the equation to values of $p$ less than 0.15 .

This cxperiment was planned with the hope that the matrices of all loadings would have the same density and hence the same conductivity as the material with 0 -vol \% particles. As Table I shows. however. this condition was not met. and the above equation was first used to calculate the matrix 
conductivity for each loading by treating additional porosity as spherical voids with a $\lambda_{;}^{\prime} \equiv 0$. For inis case the above equation reduces to

$$
\lambda^{*}=\lambda_{i} \frac{1-p^{\circ}}{1+0.5 p^{\circ}}
$$

where

$$
\begin{aligned}
& \lambda_{i}=\text { thermal conductivity of the } 0-v o l q \text { specimen, } \\
& \lambda^{\prime}=\text { thermal conductivity of the matrix material with additional porosity } p^{\prime} .
\end{aligned}
$$

Thus, the specimen with 35-vol \% particles at $400 \mathrm{~K}$ was assumed to have a matrix conductivity of

$$
\lambda^{*}=47.5 \frac{1-0.0857}{1+0.0429}=47.5(0.875)=41.6 \mathrm{~W} / \mathrm{m} \cdot \mathrm{K}
$$

since

$$
p^{\prime}=\frac{1.75 \mathrm{Mg} / \mathrm{m}^{3}-1.60 \mathrm{Mg} / \mathrm{m}^{3}}{1.75 \mathrm{Mg} / \mathrm{m}^{3}}
$$

and $\lambda_{m}^{\prime}=47.5 \mathrm{~W} / \mathrm{m} \cdot \mathrm{K}$ at $400 \mathrm{~K}$ from Table 5 . This approach yielded $\lambda_{m}$ values of $41.6,44$, and $46 \mathrm{~W} / \mathrm{m} \cdot \mathrm{K}$ for the matrices of the composite fuel elements with loadings of $35-.22-$, and $13-\mathrm{vol} \%$ respectively.

Equation B-1 was then used to calculate values of $\lambda / \lambda_{m}$ at specific values of $0.13-, 0.22-$, and 0.35-vol fraction particles for assumed values of 0,10 , and $20 \mathrm{~W} / \mathrm{m} \cdot \mathrm{K}$ for the themal conductivity of the second phase simulated fuel particles. The results of these calculations are shown in Fig. B-1. Sravoth curves were drawn between the three discrete data for each assumed value of $\lambda_{2}$. This "theoretical calculation" can be compared to the experimental results at each irradiation stage as shown. Although the "experimental value" for $\lambda / \lambda_{m}$ for the 13-vol $\%$ unirradiated specimen appears

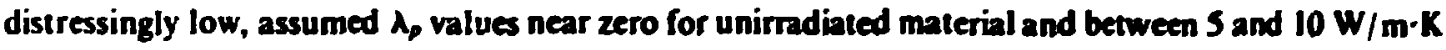
after one cycle would fit the experimental data well. This result indicates that $\lambda$ of the simulated fuel particle increases with initial fluence.

The relatively large deviation of $\lambda / \lambda_{m}$ from the experimental data on 35 -vol \% particle loading after $I$ cycle is not significant because the equation is in error at that high loading. Figure $B-1$ shows results which would indicate that $\lambda$, increases during the first cycle, decreases during the second, and then, increases rapidly up to the maximum fluence of $12.1 \times 10^{23}$ neutrons $/ \mathrm{m}^{2}$. This behavior is shown in Fig. 19 of the text.

-The "experimental value" now has an obvious hadee sinee we made an eatimate of the matrix thermal conductivities using Eq. If-3 and $47.5 \mathrm{~W} / \mathrm{m} \cdot \mathrm{K}$ for the unirmdiated spacimen of a-rol $\mathrm{F}$ loedine. 


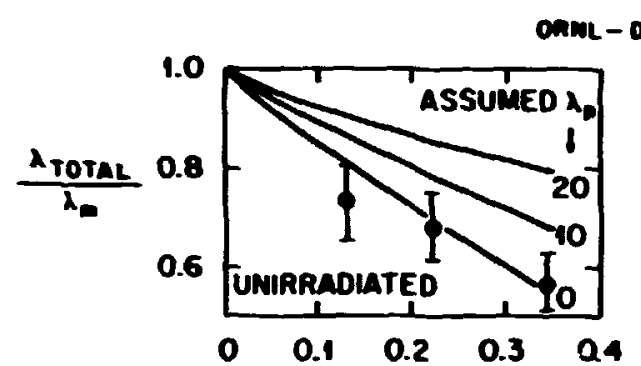

P. PARTicle VOlUME fraction
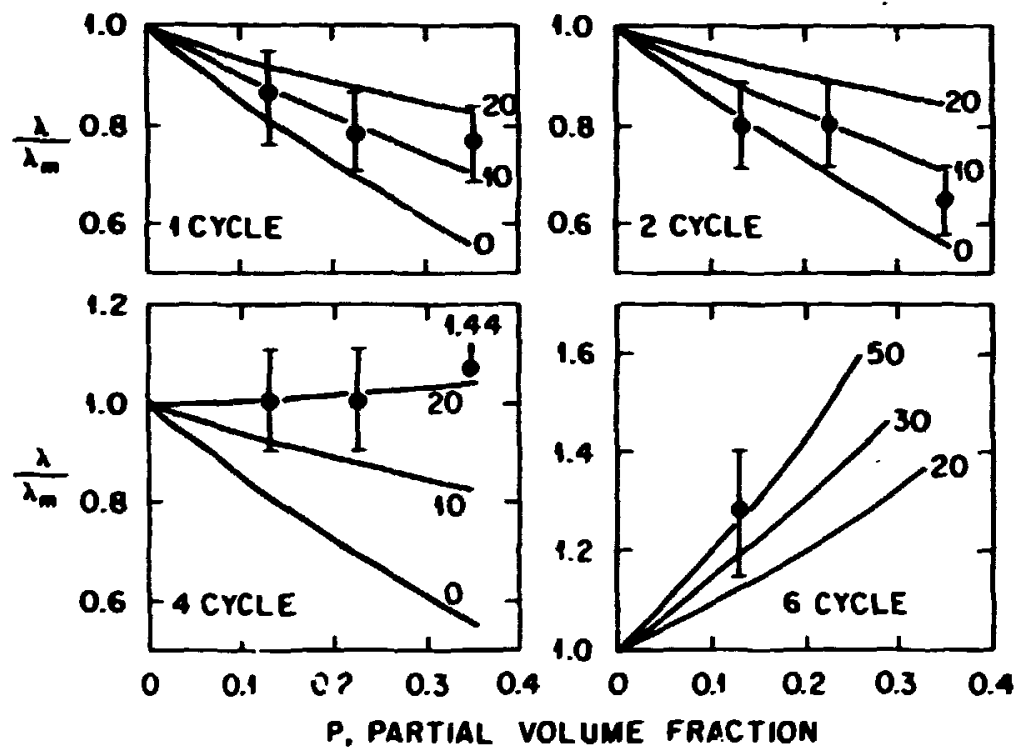

Fis B-I. Effective particle thermal conductivity, $\lambda_{p}$, showing the increase with increasing neutron fluence. This was

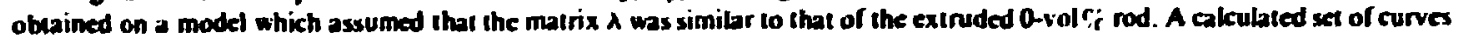
is shown for each irradiation stage. and measured values are shown for comparison.

\section{Appendix C \\ COMPARISON OF THE ELECTRICAL RESISTIVITIES OF SLUG-INJECTED RODS CONTAINING FUEL PARTICLES TO RODS CONTAINING SIMULATED PARTICLES AND TO EXTRIITED RODS}

The $\rho$ of several production specimens containing $\mathrm{ThO}_{2}$ fuel kernels was measured for comparison to the research specimens that contained inert carbon kernels. The results are given in Fig. C-I, which shows $\rho(300 \mathrm{~K})$ versus volume percent shim content. The $\rho$ of this material with 0 shim is greater than that of the research specimen formed with slug injection by $20 \%$. The two sets of production materials with $36 \%$ fuel differed by nearly $20 \%$. The extruded rods are also shown in the figure in terms of "equivalent" shim content. The great difference in the two curves merely suggests in another way that $\lambda$ of the extruded material should be much higher than $\lambda$ of the slug-injected material. This is true regardless of shim content although $\lambda$ probably increases slightly with increasing shim content. 


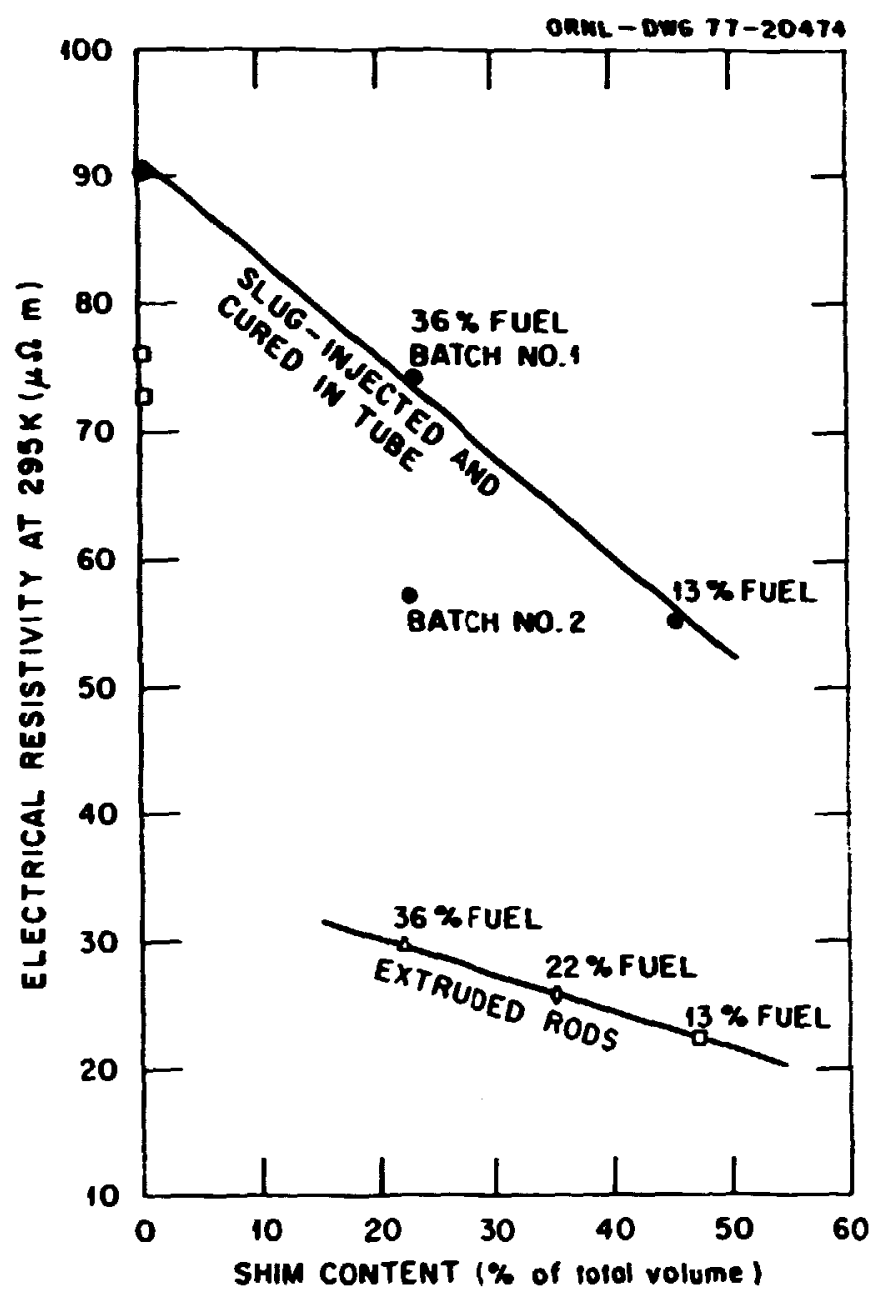

Fit. C-I. Electrical reciativity $v$ shim content for shopinjected fuel rods and vs "equivalent" shim content for exiruded fuel rods. This shows that the $\rho$ of shug-injected elements with shim added is aboul two times greater than exiruded fuel rods. 